UCRL-ID-132671

\title{
In Situ Destruction of Contaminants via Hydrous Pyrolysis/Oxidation: Visalia Field Test
}

R. L. Newmark, R. D. Aines, K. Knauss, R. Leif, M. Chiarappa,B. Hudson, C. Carrigan, A. Tompson, J. Richards, C. Eaker, R. Wiedner, T. Sciarotta

December 1, 1998

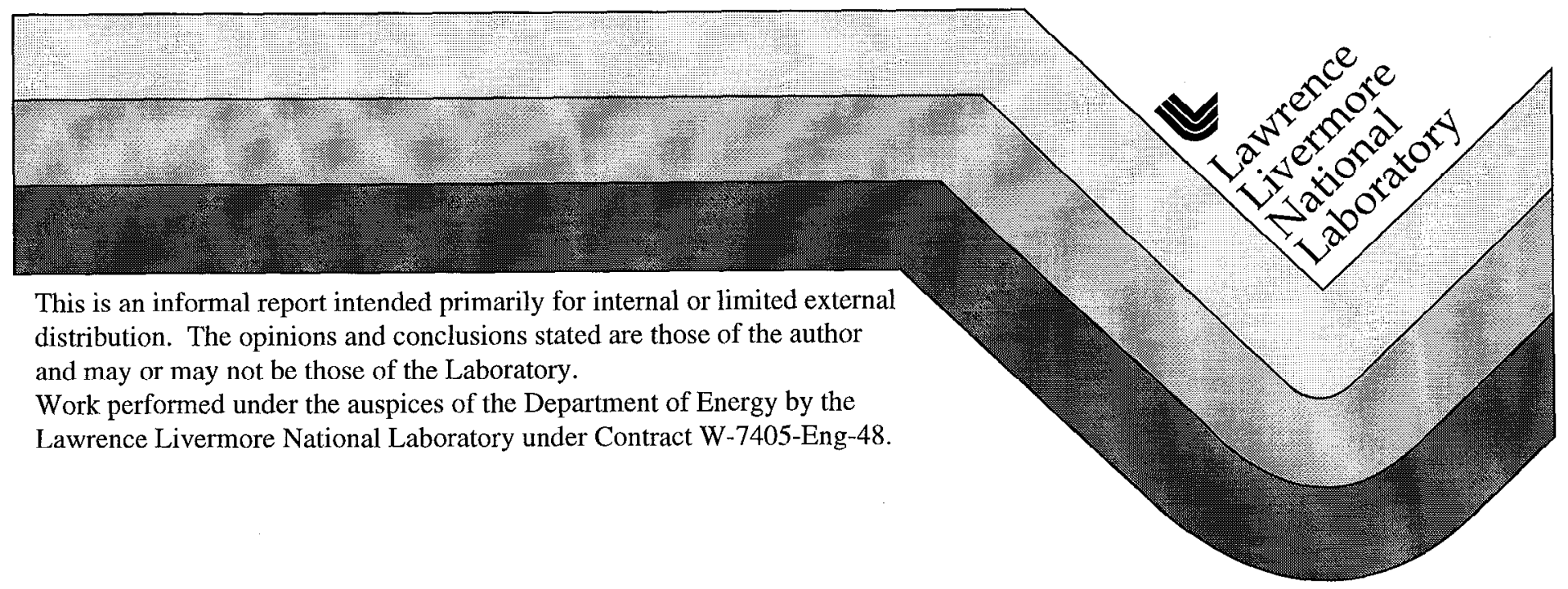




\section{DISCLAIMER}

This document was prepared as an account of work sponsored by an agency of the United States Government. Neither the United States Government nor the University of California nor any of their employees, makes any warranty, express or implied, or assumes any legal liability or responsibility for the accuracy, completeness, or usefulness of any information, apparatus, product, or process disclosed, or represents that its use would not infringe privately owned rights. Reference herein to any specific commercial product, process, or service by trade name, trademark, manufacturer, or otherwise, does not necessarily constitute or imply its endorsement, recommendation, or favoring by the United States Government or the University of California. The views and opinions of authors expressed herein do not necessarily state or reflect those of the United States Government or the University of California, and shall not be used for advertising or product endorsement purposes.

This report has been reproduced directly from the best available copy.

Available to DOE and DOE contractors from the Office of Scientific and Tecluical Information P.O. Box 62, Oak Ridge, TN 37831

Prices available from (615) 576-8401, FTS 626-8401

Available to the public from the

National Technical Information Service

U.S. Department of Commerce 5285 Port Royal Rd.

Springfield, VA 22161 


\title{
In Situ Destruction of Contaminants via Hydrous Pyrolysis/Oxidation: \\ Visalia Field Test
}

\author{
Robin L. Newmark, Roger D. Aines, Kevin Knauss, Roald Leif, \\ Marina Chiarappa, Bryant Hudson, Charles Carrigan, Andy Tompson, Jim Richards \\ Lawrence Livermore National Laboratory, Livermore, CA, 94550, USA
}

\begin{abstract}
Craig Eaker, Randall Weidner, Terry Sciarotta, Southern California Edison Company, PO Box 800, 2244 Walnut Grove Ave., Rosemead, CA., 91770
\end{abstract}

\section{Summary}

A field test of hydrous pyrolysis/oxidation (HPO) was conducted during the summer of 1997, during a commercial application of thermal remediation (Dynamic Underground Stripping (DUS)) at the Visalia Pole Yard (a superfund site) in southern California. At Visalia, Southern California Edison Co. is applying the DUS thermal remediation method to clean up a large (4.3 acre) site contaminated with pole-treating compounds. This is a full-scale cleanup, during which initial extraction of contaminants is augmented by combined steam/air injection in order to enhance the destruction of residual contaminants by HPO. Laboratory results indicate that the contaminants at Visalia react at similar rates to TCE, which has been the focus of extensive laboratory work (Knauss et al., 1998a-c). Field experimental results from this application yield valuable information (1) confirming the destruction of contaminants in soil and groundwater by HPO, (2) validating the predictive models used to design HPO steam injection systems, (3) demonstrating that accurate field measurements of the critical fluid parameters can be obtained using existing monitoring wells and (4) obtaining a reasonable prediction of the cost and effectiveness of $\mathrm{HPO}$, working at a commercial scale and with commercial partners.

The goal of our additional study and demonstration in conjunction with Edison has been to obtain early proof of hydrous pyrolysis/oxidation in the field, and validate our predictive models and monitoring strategies. This demonstration provides valuable economic and practicability data 
obtained on a commercial scale, with more detailed field validation than is commonly available on a commercially-conducted cleanup.

The results of LLNL's field experiments constrain the destruction rates throughout the site, and enable site management to make accurate estimates of total in situ destruction based on the recovered carbon. As of October, 1998, over $900,000 \mathrm{lb}$ of contaminant have been removed from the site; about $18 \%$ of this has been destroyed in situ.

\section{Background}

Southern California Edison's Visalia Pole Yard site currently contains DNAPL product composed of pole-treating chemicals (primarily creosote and pentachlorophenol) and an oil-based carrier fluid (Figure 1). Bioremediation of the free-organic liquids is expected be prohibitively slow (enhanced bioremediation was predicted to take 120 years (Edison, pers. comm.). Thermal treatment (steam injection with vacuum extraction similar to that used in the recent Dynamic Underground Stripping demonstration (Newmark, ed., 1994)) was chosen for removal of the free product contaminant. The overall objectives of the thermal remediation of the Visalia Pole Yard are to remove a substantial portion of the DNAPL contaminant at the site, thereby enhancing the bioremediation of remaining contaminant, and to significantly shorten the time to site closure as well as improving the accuracy of the prediction of time to closure. As part of the final removal process, Southern California Edison Co. (Edison) is also implementing hydrous pyrolysis (HPO), an in situ method of destroying organic contaminants using small amounts of supplemental air or oxygen (Knauss et al., 1998-c). The primary use of HPO at this site is for destruction of residual pentachlorophenol, which will not readily steam strip due to high solubility and low vapor pressure. The combination of rapid recovery and thermal destruction is expected to permit Edison to achieve their cleanup goals (Figure 2). 
Because the Visalia site is physically very similar to the recently completed demonstration of thermal remediation at the LLNL gasoline spill site, the physical aspects of the remediation are anticipated to be very similar. The ability to uniformly heat the LLNL site gave great certainty that this goal can be accomplished at Visalia. Although the site is approximately 2-3 times larger, the issues are similar. The LLNL experience also confirmed that the process could be accurately monitored and controlled. The chemical differences in the contaminant were the basis for a laboratory feasibility study (Leif et al., 1997a). During an extensive laboratory study of hydrous pyrolysis of the Visalia pole yard contaminant suite (described below), all of the contaminants have been observed to be degradable by HPO.

At the Visalia Pole Yard, there is DNAPL contamination in three distinct water-bearing zones (Figures 1 and 3) (Geraghty and Miller, 1992, Vol. 1, Figure 12.1). Here we consider the several shallow aquifers as one unit from about 35 to 75 feet below ground surface, and the intermediate aquifer from about 75 to 105 feet below ground surface (Figure 3). The most shallow contamination (above 35 feet in depth), was not directly targeted for thermal methods (bioremediation is working well enough at this depth). The most sensitive ground water resource is found in the deep aquifer, below about 120 feet. The thermal remediation system was designed to remove contaminant from the intermediate and shallow aquifers, without disturbing the deep aquifer.

The operational plan was to remove as much free-product pole treating compound as possible by steam injection/vacuum extraction. Figure 4 shows the injection/extraction layout and the approximate contours of free-product contamination in the three permeable levels shown in Figure 3 (the uppermost level is not being directly treated). Estimates place between 40,000 and 80,000 gallons of pole treating chemical in the soil (Eaker, pers. comm.). During the initial contaminant extraction phase, about $380,000 \mathrm{lb}$ (or $47,000 \mathrm{gal}$ ) of pole-treating chemicals were removed in approximately five months. Following this initial contaminant removal by steam 
injection and vacuum extraction, air was injected along with the steam to enhance hydrous pyrolysis of the remaining contaminant.

The goal of our additional study and demonstration in conjunction with Edison's full-scale cleanup was to obtain early proof of hydrous pyrolysis in the field, and validate our predictive models and monitoring strategies.

\section{Chemical Basis for Hydrous Pyrolysis/Oxidation}

We have been conducting research on the in situ thermal degradation of petroleum distillates (gasoline, diesel fuel, etc.) and chlorinated hydrocarbons (trichloroethene (TCE), tetrachloroethene (PCE), TCA, PCB, etc.)(Knauss et al., 1997, 1998a-c, Leif et al., 1997a, 1997b). Experimental work with organic solvents (e.g., Knauss et al., 1998a-c) suggests that in situ thermal degradation of these compounds via hydrous pyrolysis/oxidation (HPO) may form the basis for a whole new approach to remediation. We are studying the base rates of degradation at temperatures achieved by thermal remediation techniques and methods to catalyze the chemical processes to maximize degradation. This approach provides the basis for dramatically improving the rate and efficiency of remediation by rendering the hazardous materials into benign ones via a completely in situ process. By determining the thermodynamic properties (e.g., solubility, Henry's Law constants, etc.) of these hazardous compounds, as a function of T and P, we hope to be able to predict effectiveness and required cleanup time for design purposes and to optimize cleanup through the use of process-oriented hydrologic transport and geochemistry models. In spite of recent advances in modeling capabilities, the thermodynamic data necessary to make design calculations for elevated temperatures are essentially nonexistent.

Several in situ methods for cleaning up volatile organic contaminants involve the application of either heat alone or heat plus water and/or steam to mobilize organic contaminants. This approach is essentially based on the physical properties of the VOCs. As the name implies, they volatilize. A fact that is less well-recognized, however, is that organics are increasingly solvated by and reactive with water as temperature is increased. This occurs largely as a consequence of 
the precipitous drop in the dielectric constant of water as temperature increases. Water becomes a progressively better and better solvent for organics with increasing temperature. Under appropriate conditions, water and/or dissolved oxygen can react with hazardous organics to produce a relatively benign mixture of oxygenated compounds (e.g., alcohols, aldehydes and/or carboxylic acids). The yield of benign products resulting from the hydrothermal oxidation of hazardous organics may be enhanced using a variety of oxidants.

The ultimate closure of the Visalia Pole Yard site depends upon the removal of PAH compounds (e.g., naphthalene) and pentachlorophenol to levels meeting the drinking water standards ${ }^{1}$. Moreover, Southern California Edison Co. must be able to convincingly argue that the levels will remain low in the future, with no "rebound" effect as has been seen in pump-and-treat remediation of DNAPL sites. The combination of DUS and HPO should meet these objectives and provide confidence that the contaminant levels will stay within predicted limits in the future. In order to predict the continued HPO destruction of residual contaminants, a detailed understanding of the reactions and their sensitivity to site conditions is desired. What follows is a brief introduction to the chemical basis for HPO.

\section{Theoretical Basis for Hydrous Pyrolysis/Oxidation:}

Organic compounds in the environment are frequently metastable. Thermodynamically, they should oxidize to their mineral (stable) components, such as $\mathrm{CO}_{2}$, but the kinetics of these reactions are slow. Dolfing and Janssen (1994) used group contribution estimation techniques to calculate the free energies of formation of the aqueous and gas phase aliphatic chlorinated hydrocarbons. The estimates are for $25^{\circ} \mathrm{C}$ and 1 bar. Using these data, we can write possible hydrolysis and oxidation reactions involving compounds like TCE and calculate their thermodynamic driving force. For example, for a reaction written in the form:

\footnotetext{
${ }^{1}$ The Remediation Standards listed in the current Remedial Action Plan / Record of Decision (RAP/ROD) are as follows: pentachlorophenol: $17 \mathrm{mg} / \mathrm{kg}$ in soil, $1 \mathrm{ug} / \mathrm{L}$ in water

TCDD (eqv): $0.001 \mathrm{mg} / \mathrm{kg}$ in soil, $0.00003 \mathrm{ug} / \mathrm{L}(30 \mathrm{ppq})$ in water

Benzo-a-pyrene: $0.390 \mathrm{mg} / \mathrm{kg}$ in soil, $0.2 \mathrm{ug} / \mathrm{L}$ (200ppt) in water (C. Eaker, pers. comm.)
} 


$$
\begin{aligned}
& \text { Reactants }=\text { Products } \\
& \Delta \mathrm{G}_{\text {reaction }}=\Sigma \Delta \mathrm{G}_{\text {products }}-\Sigma \Delta \mathrm{G}_{\text {reactants }}
\end{aligned}
$$

We made such calculations for a number of potentially interesting aqueous oxidation reactions and found that for many of them, at $25^{\circ} \mathrm{C}$, there was a significant driving force. This fact alone, of course, doesn't mean that the reaction will, in fact, proceed as written for a number of reasons. First, this is an estimate of the thermodynamic driving force for the reaction at reference state conditions of temperature and pressure and with unit activities and fugacities for all species in the reactions. Second, we are not considering any kinetic inhibition of the reactions. Nevertheless, the calculations are a starting point for discussion.

Consider the following aqueous phase reaction (at $25^{\circ} \mathrm{C}$ ) involving naphthalene:

$$
\begin{aligned}
& \mathrm{C}_{10} \mathrm{H}_{8}(\mathrm{aq})+12 \mathrm{O}_{2}(\mathrm{aq})=10 \mathrm{CO}_{2}(\mathrm{aq})+4 \mathrm{H}_{2} \mathrm{O} \\
& \Delta \mathrm{G}=-1249.6 \mathrm{kcal} / \mathrm{mol}
\end{aligned}
$$

Under the conditions of temperature, pressure and activity/fugacity implied in the calculation, this reaction has a significantly negative free energy of reaction, i.e., it is energetically favored.

Similar reactions may be written for many other $\mathrm{PAH}$ and chlorinated aromatic hydrocarbons and we have done these calculations as well. The results encouraged us to pursue experiments to investigate the hydrous pyrolysis/oxidation of Visalia pole tar.The potential for oxidizing these compounds is now obvious (only recently, owing to a lack of thermodynamic data precluding calculations), but the rate at ambient conditions is negligible. Other remedial methods have focused on the reductive destruction of these compounds principally because the activation energy for oxidative reactions is large. However, at $100^{\circ} \mathrm{C}$, the activation barriers are small enough that the reactions proceed to completion rapidly. 


\section{Preliminary Experiments with Visalia Pole Tar}

Preliminary results of hydrothermal oxidation using dissolved $\mathrm{O}_{2}$ show that naphthalene and pentachlorophenol (model compounds for the components of pole tar) can be rapidly and completely degraded (given sufficient $\mathrm{O}_{2}$ ) to benign products at moderate conditions, easily achieved in thermal remediation. These are the two most abundant compounds in the main classes of compounds that comprise Visalia free product DNAPL. The initial emphasis was on determining the rate dependency on dissolved $\mathrm{O}_{2}$ at temperatures easily achieved in thermal remediation $\left(100^{\circ}\right.$ and $\left.125^{\circ} \mathrm{C}\right)$. We found that at dissolved $\mathrm{O}_{2}$ concentrations as high or higher than the stoichiometric amount required to oxidize the dissolved naphthalene or pentachlorophenol, the rates were independent of $\mathrm{O}_{2}$ concentration. Figure 5 shows a comparison of the reaction rates of pentachlorophenol and napthalene (Visalia model compounds) to the rate observed under similar conditions for TCE. Note that for a given temperature, naphthalene oxidation is considerably slower than pentachlorophenol oxidation. The rates for Visalia compounds bracket the TCE value; this indicates that the overall reaction rates at Visalia will be appropriate for extrapolation of the results to TCE cleanup.

Figures 6 and 7 show results from a napthalene and a pentachlorophenol run which contained enough dissolved $\mathrm{O}_{2}$ (air saturation) to completely oxidize the starting amount of the hydrocarbon. Note that in both the naphthalene and pentachlorophenol runs, we control $\mathrm{pH}$ at pH 7 using a dilute buffer solution. The amounts of $\mathrm{CO}_{2}$ and chloride ion eventually produced suggest that "mineralization" is nearly complete. In these experiments, pentachlorophenol is observed to rapidly degrade at temperatures as low as $70^{\circ} \mathrm{C}$. Oxidation of napthalene showed no byproducts other than $\mathrm{CO}_{2}$ and chloride ion in the runs that had at least the stoichiometrically required amount of dissolved $\mathrm{O}_{2}$. Ephermeral intermediate products may have been present at low concentrations. 
Experiments using real Visalia Pole Yard pole treating chemical samples showed them to be amenable to in situ destruction, again given sufficient dissolved $\mathrm{O}_{2}$. Dissolved $\mathrm{O}_{2}$ reacted extensively with the compounds present in pole tar to form oxygenated products ranging from oxygenated intermediates, like phenols and carboxylic acids, to the ultimate product $\mathrm{CO}_{2}$. Figure 8 shows results from one of the preliminary experiments from a study of oxidation of pole tar compounds (Leif et al., 1998) found in the Visalia free product. In these runs, oxygen gas was added to the system to establish an initial concentration of $18.5 \mathrm{umols} / \mathrm{g}$. The pressure was maintained at 500 psi to keep the oxygen, and any product gas, in solution. This low pressure has no effect on the chemical reactions being measured. In the run whose data is plotted in Figure 8 , free product pole tar was added to the Dickson autoclave in an amount exceeding the oxygen content of the water. This ensured that the oxidation reaction stopped before going to completion, allowing examination of intermediate products of the reaction. The temperature is increased as shown, until the reaction rate as measured by the production of carbon dioxide gas became rapid at $100^{\circ} \mathrm{C}$. Most of the oxygen was consumed at this temperature. More complete analyses are given in Figure 9 and Table 1. The data are labeled as "partially reacted water". All chemicals measured by EPA 8270 were reduced by the hydrous pyrolysis reaction. The only new products formed, other than $\mathrm{CO}_{2}$, were oxygenated phenols and carboxylic acids, which are innocuous compounds.

We also evaluated the results of partial oxidation of the contaminants, both to gain insight into the reaction mechanism(s) and to confirm that the intermediates of reaction were benign. The free product was equilibrated with water by stirring overnight. The water was decanted and placed in the bomb (no free product present). The sample was initially heated in the presence of insufficient oxygen for complete oxidation (partially reacted water). The dissolved $\mathrm{O}_{2}$ readily reacts with the primary creosote compounds (such as napthalene, methylnapthalene, anthracene and fluorene), forming products ranging from partially oxidized intermediates, such as phenols and benzoic acid to the fully oxidized product, $\mathrm{CO}_{2}$. A separate experiment was conducted with sufficient oxygen to fully oxidize all the compounds. As seen in the results contained in Figure 9 
and Table 1 - identified as "fully/completely reacted water", none of the hydrocarbons or chlorinated hydrocarbons initially detected in the equilibrated (unreacted) contaminated water remained following the hydrothermal treatment. Sufficient oxygen was present to oxidize them all. Complete destruction of creosote was achieved at $120^{\circ} \mathrm{C}$. 
Table 1

\begin{tabular}{|c|c|c|c|c|c|c|}
\hline Chemical & \begin{tabular}{|l|} 
Free Product \\
Equilibrated \\
Water \\
$\mathrm{g} / \mathrm{L}$ \\
\end{tabular} & \begin{tabular}{|l|} 
\\
$\%$ \\
Observed
\end{tabular} & \begin{tabular}{|l|} 
Dissolved Product \\
Partially Reacted \\
Water \\
$\mathrm{g} / \mathrm{L}$ \\
\end{tabular} & \begin{tabular}{|l|} 
\\
$\%$ \\
Observed \\
\end{tabular} & $\begin{array}{l}\text { Reportable } \\
\text { Limit } \\
\text { g/1 }\end{array}$ & $\begin{array}{l}\text { Completely } \\
\text { Reacted Water } \\
\text { g/L }\end{array}$ \\
\hline Phenol & & $0.0 \%$ & $1.09 \mathrm{E}-06$ & $14.35 \%$ & $<3.2 E-08$ & non-detect \\
\hline 2-Methylphenol & & $0.0 \%$ & $1.35 \mathrm{E}-07$ & $1.78 \%$ & $<3.2 E-08$ & non-detect \\
\hline 4-Methylphenol & & $0.0 \%$ & $3.01 \mathrm{E}-07$ & $3.96 \%$ & $<3.2 E-08$ & non-detect \\
\hline $\begin{array}{l}\text { 2,4-Dimethyl- } \\
\text { phenol }\end{array}$ & & $0.0 \%$ & 5.20E-08 & $0.68 \%$ & $<3.2 E-08$ & non-detect \\
\hline Benzoic Acid & & $0.0 \%$ & $4.16 \mathrm{E}-07$ & $5.48 \%$ & $<3.23 E-07$ & non-detect \\
\hline Napthalene & 5.29E-06 & $34.5 \%$ & 7.39E-07 & $9.73 \%$ & $<3.2 E-08$ & non-detect \\
\hline $\begin{array}{l}\text { 2-Methylnap- } \\
\text { thalene }\end{array}$ & 3.14E-06 & $20.5 \%$ & 5.62E-07 & $7.40 \%$ & $<3.2 E-08$ & non-detect \\
\hline Acenapthene & $1.44 \mathrm{E}-06$ & $9.4 \%$ & $2.48 \mathrm{E}-07$ & $3.26 \%$ & $<3.2 E-08$ & non-detect \\
\hline Dibenzfuran & 7.95E-07 & $5.2 \%$ & $2.62 \mathrm{E}-07$ & $3.45 \%$ & $<3.2 E-08$ & non-detect \\
\hline Flourene & 7.22E-07 & $4.7 \%$ & $1.76 \mathrm{E}-07$. & $2.32 \%$ & $<3.2 E-08$ & non-detect \\
\hline Phenanthrene & $1.94 \mathrm{E}-06$ & $12.7 \%$ & $1.74 \mathrm{E}-06$ & $22.91 \%$ & $<3.2 E-08$ & non-detect \\
\hline Anthracene & $2.26 \mathrm{E}-07$ & $1.5 \%$ & $1.25 \mathrm{E}-07$ & $1.65 \%$ & $<3.2 E-08$ & non-detect \\
\hline $\begin{array}{l}\text { Di-nButylph- } \\
\text { thalate }\end{array}$ & & $0.0 \%$ & 8.70E-08 & $1.15 \%$ & $<3.2 E-08$ & non-detect \\
\hline Fluoranthene & $8.36 \mathrm{E}-07$ & $5.5 \%$ & 9.11E-07 & $11.99 \%$ & $<3.2 E-08$ & non-detect \\
\hline Pyrene & $6.10 \mathrm{E}-07$ & $4.0 \%$ & 4.91E-07 & $6.46 \%$ & $<3.2 E-08$ & non-detect \\
\hline $\begin{array}{l}\text { Benzo (a) Anthra- } \\
\text { cene }\end{array}$ & $1.48 \mathrm{E}-07$ & $1.0 \%$ & 9.70E-08 & $1.28 \%$ & $<3.2 E-08$ & non-detect \\
\hline Chrysene & $1.78 \mathrm{E}-07$ & $1.2 \%$ & $1.64 \mathrm{E}-07$ & $2.16 \%$ & $<3.2 E-08$ & non-detect \\
\hline $\begin{array}{l}\text { Benzo (b and } k \text { ) } \\
\text { Fluoranthenes }\end{array}$ & & & & & $<1.61 E-07$ & non-detect \\
\hline Benzo (a) Pyrene & & & & & $<1.61 E-07$ & non-detect \\
\hline Total Detected & $1.53 \mathrm{E}-05$ & $100 \%$ & $7.60 \mathrm{E}-06$ & $100 \%$ & $1.189 E-06$ & \\
\hline \multicolumn{3}{|l|}{ Destruction } & \multicolumn{2}{|l|}{$50 \%$} & \multicolumn{2}{|l|}{$>92 \%$} \\
\hline
\end{tabular}

EPA Method 8270A, Calscience Environmental Laboratories, Inc, 2/1/96.

Table 1. Results of hydrous pyrolysis/oxidation testing of water saturated with poletreating chemicals. "Equilibrated Water" was stirred with an excess of free-product (from a Southern California pole-treating site) for three days. "Partially Reacted Water" is the result of reacting the free-product/water mix at up to $120 \mathrm{C}$ until all oxygen was consumed, stopping the reaction. "Completely Reacted" used the decanted, equilibrated water (no free product) with an excess of oxygen. 
In order to model the transport of the PAH compounds, thermodynamic properties of key constituents are required at the appropriate temperatures. We determined the high-tempreature aqueous solubility of a representative PAH compounds commen in the Visalia pole tar; fluorene. Figure 10 shows the experimental results; they agree well with the published data in the lower temperature range.

\section{Application of Hydrous Pyrolysis to the Visalia Cleanup}

The laboratory results indicated that hydrous pyrolysis can play a significant role in the final removal, or polishing of residual contaminant from the soil. This is generally viewed to be the most difficult part of a cleanup. Where groundwater is oxygenated (i.e., at the edges of the contaminated area, the up-gradient side in particular), hydrous pyrolysis will occur during the initial steaming of the site. After the majority of the product is removed from the site, this process continues. Oxygen can be added to the injected steam to promote the hydrous pyrolysis reaction after collapse of the steam zone. The injected oxygen dissolves in water held as residual saturation during the steam injection pulse, and can readily diffuse from that water into the rest

of the aqueous phase after collapse of the steam zone. Thus, the supplemental oxygen can be readily delivered to the heated "reaction zone". Because of the difficulty of extracting pentachlorophenol by vapor extraction, its destruction by hydrous pyrolysis was anticipated to be a significant factor in the final cleanup of the Visalia site.

\section{Hydrous Pyrolysis at Visalia: Field Experiments}

In order to evaluate the progress of the HPO chemical destruction in situ, we conducted two field experiments at the Visalia site. We also developed field methods for sampling and analyzing hot water for contaminants, intermediates and products of reaction. Since HPO is an aqueous-phase reaction, it is essential to capture the fluid chemistry for evaluation. At elevated temperatures, many of the key constituents are sufficiently volatile that traditional sampling techniques are not suitable. We developed two high temperature packer and pump systems capable of delivering a 
pressurized, isolated fluid stream to the surface, where in-line analysis can be performed (Figure 11). In order to measure key chemical constituents, an in-line analytical system was developed for both dissolved oxygen and organic analyses (Figure 12). This system depends largely on a manifold maintaining pressures above hydrostatic on the fluid stream until analyses are performed (for example, this involved keeping pressure on the sample stream until a fixed volume sample was collected in a purge and trap collection mode for the gas chromatograph).

For use at Visalia, an additional challenge posed was to protect the existing plastic monitoring wells from temperature-induced collapse. We modified the packer systems to provide circulating cooling fluids to both protect these wells and to permit sampling during steam injection. By separating the straddle packers, we were able to protect four plastic monitoring wells, placing the packers in position above the heated region. The two pump systems enabled sampling in two wells, which were screened in the intermediate aquifer. These systems have performed successfully to date (during the first year of steam operations), both protecting the wells and providing valuable fluid samples, thus demonstrating the capability of monitoring these processes using existing wells. This provides for historical consistency in evaluating the groundwater concentrations as well as a significant cost savings.

Since the addition of air or oxygen to the contaminated region is a critical aspect of HPO, noble gas tracers (Xe, $\mathrm{Kr}, \mathrm{Ne}$ and $\mathrm{He}$ ) were used to track the movement of the steam (and subsequent condensation to liquid water) and other gases initially present in the steam. This has become particularly important as the HPO testing is being conducted in parallel with a full-field steam mobilization. In most experiments in which some additive (such as nutrients or oxidative chemicals) is introduced into the subsurface after which the chemical contamination is observed to decrease, it is difficult to definitively attribute the decrease in contaminant concentration to a particular process. Introducing fluid into the subsurface can dilute and/or displace the native groundwater; contaminant destruction cannot be quantified without some means of identifying the fluids present. The tracers are utilized to identify those fluids directly derived from the injectate of interest, as opposed to native fluids or condensate from injection wells elsewhere in 
the field. They permit us to follow the injected steam/water/oxygen pattern from a single injection well, measuring how well mixing occurs, how oxygen is consumed and carbon dioxide produced/transported, how the intermediate HPO destruction products correlate with temperature and oxygen, and in identifying the isotopic content of the extracted carbon forms. Isotopic measurements made on samples of the extracted carbon forms with regard to both carbon 14 and carbon 13 determines the mass of carbon derived from contaminant oxidation as opposed to (modern) atmospheric gas origins. The combination of accurate fluid sampling and tracking of the injected fluids allowed us to determine the amount of in situ destruction occurring in the treated region.

\section{Modeling}

The subsurface conditions are complex, involving multiple phases and phase changes combined with mass and heat transport. We used advanced numerical modeling in order to interpret the results of the experiments. These calculations are based on a non-isothermal, unsaturated zone transport code (NUFT), which includes individual gas properties in the multi-phase system. Model calculations give tracer concentrations in time and space that are directly comparable to measurements. The experimental results show remarkably close agreement with the simulations. The modeling predicted steam and tracer movement to within an hour or two in most instances. Modeling also effectively predicted the time of "thermal breakthrough", which occurs when sufficient heat has built up in the subsurface for vaporization of contaminants to begin, and "steam collapse", which is the opposite phenomenon, reflecting the condensation of the steam zone (Figure 13).

The full thermal/hydrological/HPO reaction capabilities of the NUFT code permit us to make detailed predictions of the expected behavior at Visalia (Figure 14). Among the types of predictions we test are those concerning the relationship between mixing, presence of steam condensate, and HPO reaction rate. These are the important parameters for determining that there is sufficient oxygen mixing with contaminated fluid (instead of displacing the contaminated 
fluid with steam condensate) and that the hydrous pyrolysis reaction is proceeding in the contaminated fluids.

Figure 14 shows some key results prepared for the Visalia test. Pancl 14A shows the extent of the steam zone after 8 hours of injection at 3.4 bars injection pressure. The area where liquid water saturation is below 1 indicates presence of steam. At this point in the simulation, injection is stopped and the steam zone is allowed to collapse until no steam is present (all the heated zone is liquid filled again). The distribution of temperature 16 hours after steam injection ceases is shown in Figure 14B; the heated zone is slightly larger than the original zone containing live steam. Note that the collapse of cold water back into that zone did not noticeably shrink the zone, since the heat capacity of the soil is so much greater than that of the small amount of water flowing through it. The temperature decreases to the boiling point of water at the applied pressure. Panel 14C shows the extent of oxygen-saturated water at this point, assuming that 100 ppm (by weight) of oxygen or air was injected along with the steam. The oxygen is fully distributed in the heated "reaction" zone, as well as in the area beyond the extent of the original steam zone where cold, condensed steam which is oxygen saturated was located. These predictions give us specific parameters to test in the field, and allow a more detailed understanding of the field experiments by delineating the type of phenomena (such as the cold, oxygen saturated leading wave) that our instruments may be expected to detect.

\section{First Experiment: Mixing and Dispersion}

A key question in the design of in situ HPO systems is the degree to which the heat, oxygen and contaminant can be mixed. Strong dispersive mixing of oxygen, contaminant and hot water is a critical aspect in promoting HPO. Initial concerns focused on whether or not piston-like flow conditions would dominate, which would reduce the mixing zones crucial to the success of HPO as an in situ remediation technique. The first tracer experiment was designed to address hydrology issues of mixing and dispersion (Figure 15). 
About 80,0001 of xenon-tagged water was introduced to injection well S4 (Figure 4), screened from 80 to $100 \mathrm{ft}$ (Table 2). This was followed by neon-tagged steam injection. The tracers were chosen based on their solubilities; high-solubility xenon will mimic the aqueous phase, where low-solubility neon will mimic the vapor phase. Sampling was conducted in wells MW36 (a plastic-cased monitoring well about $24 \mathrm{~m}$ away) and S13 (a steel-cased extraction well about $28 \mathrm{~m}$ away) until the steam front had passed beyond both monitoring wells. Steam injection ceased, and the front was permitted to collapse back to the injection well. The timing of these events can be found in Table 2. Fluid samples were evaluated for the presence of tracers, intermediates of reaction, contaminant concentration, and dissolved oxygen.

Table 2

\begin{tabular}{|c|c|}
\hline Date and Time & Event \\
\hline $\begin{array}{l}\text { First Tracer Experiment: } \\
\text { Mixing and Dispersion }\end{array}$ & \\
\hline 5/19/97 15:55 & Xenon tracer injection begun \\
\hline $5 / 20 / 97 \quad 13: 30$ & Xenon tracer injection complete \\
\hline 5/21/97 8:00 & Steam and Neon injected into Well S4 \\
\hline $5 / 23 / 976: 15$ & Well $\$ 13$ exceeds $100^{\circ} \mathrm{C}$ (steam passes well) \\
\hline $5 / 23 / 97 \quad 6: 40$ & Injection is halted and steam zone collapses \\
\hline $\begin{array}{l}\text { Second Tracer Experiment: } \\
\text { Hydrous Pyrolysis / Oxid }\end{array}$ & tion \\
\hline $6 / 17 / 978: 00$ & $\begin{array}{l}\text { Steam, Krypton, and Helium tracer injection } \\
\text { begins in Well S4 }\end{array}$ \\
\hline $6 / 19 / 97 \quad 13: 33$ & Well $\$ 13$ exceeds $100^{\circ} \mathrm{C}$ (steam passes well) \\
\hline $6 / 20 / 97 \quad 10: 37$ & Injection is halted and steam zone collapses \\
\hline
\end{tabular}

Table 2. Time history of the two tracer experiments. 
Large dispersive mixing of the tracers was observed (Figure 16). This is in good agreement with calculations when realistic random permeability field realizations are used in the subsurface model. Calculations using uniform media underestimate dispersive mixing by more than a factor of ten, in clear contrast to field measurements. We found that the ratio of tracer gas to natural air mixed into water was much greater than predicted by the model's initial assumption of no mixing of the injected steam and native groundwater, showing the process to be more efficient than envisioned and favoring the success of HPO in the field (Figure 17). In short, the results of this first experiment yielded excellent results favoring the success of HPO in the field.

\section{Second Experiment: Hydrous Pyrolysis / Oxidation}

The focus of the second tracer experiment was on hydrous pyrolysis/oxidation. Compressed air was injected along with the steam, in order to enhance HPO. Both helium and krypton were injected along with the steam and compressed air; the tracer solubilities mimic the aqueous and vapor phases in a similar manner to the xenon and neon used in the first experiment (Figure 18). Once again, the gradual increase in tracer concentrations support significant mixing and dispersion.

\section{Oxidation Results}

Evidence of the progress of HPO comes from a number of sources, including the disappearance of dissolved oxygen (consumed through the HPO reactions), the appearance of oxidized intermediates, the production of carbon dioxide (a final product of HPO), and the isotopic provenance of the carbon it contains (indicating the destruction of contaminant rather than other carbon sources). In the second experiment, steam injection was supplemented with air injection, increasing the dissolved oxygen available for HPO. Positive evidence of HPO was found on all counts (see below). A surprising finding was evidence of HPO occurring during and after the first, hydrology-focused experiment, which did not include the supplemental air (and thus oxygen). 
In order to evaluate the potential of commercially-available oxygen sensors to be used to monitor dissolved oxygen in the harsh conditions created in situ, we tested a suite of devices in-line during the experiments, including an experimental fiber-optic system developed for biomedical use Ferguson et al., 1998). In addition, we were able to measure dissolved oxygen with the Membrane Inlet Mass Spectrometer (MIMS) system (system design described in Kana et al., 1994). We present a subset of these measurements here (Figure 19). Dissolved oxygen decreased in fluids after steam collapse, indicating the consumption of oxygen during HPO.

Concentrations of oxidized intermediates in the Edison extraction wells increased dramatically when Edison shut off the steam in the western wells in mid July. For example, the proportion of fluorenone (a partial oxidation product of fluorene) increased markedly after steam injection (Figure 20).

Simple oxidates included in the EPA 8270 method (benzoic acid, phenol, methyl phenols) were observed to comprise up to almost $1 \%$ of the extracted organics. These intermediates have a short lifetime, so a $1 \%$ concentration represents a large, but as yet unquantified, destruction rate. Mobilization of contaminants is readily apparent in measurements made in the MW36 sample stream (Figure 21). In addition, the concentration of oxidate intermediates increases immed iately post-collapse.

Carbon dioxide, the final product of the HPO reaction, was measured in the vapor phase present in both the injection well and in the primary extraction well used for LLNL's testing. This steamrich vapor consists of a steam-carbon-dioxide mixture with small amounts of air. The extraction well also contained large amounts of oxidized intermediate products.

The combined results from the chemical and istopic measurements of oxidation at Visalia indicate that hydrous pyrolysis/oxidation of creosote compounds in ground water occurs readily at steam-derived temperatures of 100 to $110^{\circ} \mathrm{C}$. This results is consistent with the observed 
laboratoy rates of degradation. The heated Visalia ground water system is observed to be saturated with both calcium carbonite (calcite) and dissolved air. Newly created inorganic carbon (carbon dioxide or bicarbonate) was determined by the change in isotopic composition of the ground water, with measurements of the vadose zone gas and precipitated calcite supporting the ground water analyses. During and directly after injection of steam into an oxygenated subsurface aquifer, ${ }^{14} \mathrm{C}$ and ${ }^{13} \mathrm{C}$ ratios were observed to change by approximately $20 \%$ toward the composition of the hydrocarbon contaminant at the site, implying a total carbon oxidation of 12 and $7 \mathrm{ppm}$ in two experiments. This large value requires that active exchange of fresh air was occurring in the aquifer to supply the added oxygen (36 and $21 \mathrm{ppm}$ total, respectively) required to oxidize this amount of PAH-carbon (Aines et al., 1998).

\section{Relationship to Edison's Remediation Results for the Entire Site}

The results of LLNL's field experiments can be applied directly to the overall recovery in the Visalia field. Edison achieved full initial heating of the Visalia site by the end of July, 1997 (approximately 500,000 cubic yards at a temperature of $100^{\circ} \mathrm{C}$ or above). Uniform heating of both aquifer and aquitard materials was achieved (Figure 22). At this point, about 20,000 gallons of free-product liquid had been removed, which is currently stored in temporary tanks on site. Vapor and water streams continued to be saturated with product. Continued destruction by HPO was indicated by high levels of carbon dioxide ( $0.08-0.12 \%$ by volume) removed through vapor extraction. Initial destruction accounted for about $300 \mathrm{lbs} /$ day of contaminant being destroyed via HPO. At this point, Edison adopted a huff and puff mode of operation, where the steam is injected for about a week, and then injection ceases for about a week while extraction continues. Maximum contaminant removal is obtained during this steam-off period as the formation fluids flash to steam under the applied vacuum of about 1/4 atmosphere (at 2500 scfm). In September, 1997, Edison began providing supplemental oxygen as compressed air along with steam injection; in situ destruction rates increased to about $800 \mathrm{lbs} / \mathrm{day}$. Oxygen concentrations in the central extraction well, S14, were still well below $1 \mathrm{ppm}$, indicating that HPO was still limited by oxygen availability. 
By evaluating the carbon balance throughout the system, we are able to quantify the extent of in situ oxidation of PAHs at Visalia. These analyses are described in detail in Aines et al., 1998; the following is a summary. Isotopic analyses of Visalia effluent samples determined that a substantial amount of the extracted carbon dioxide derived from contaminant oxidation (Figure 23). Taking into account the difference between the isotopic signatures of the Visalia groundwater and free product contaminant, an estimate can be made of the amount of carbon dioxide generated by the oxidation of creosote; such an estimate was performed for the period between August 1 and October 14, 1997. By balancing the depletion of "modern" carbon, we estimate that $10,100 \mathrm{~kg}$ of the extracted carbon dioxide was generated by oxidation of organic contaminants.

By evaluating the carbon sources and sinks in the Visalia field (Figure 24), a geochemical carbon balance can be calculated, based on carbonate solubility alone. This is nearly independent of the isotopic signature based estimate just presented. The background Visalia ground water will exsolve $\mathrm{CO}_{2}$ if heated. This amount of $\mathrm{CO}_{2}$ must be subtracted from the total to calculate the amount of $\mathrm{CO}_{2}$ from in situ oxidation. For the same time (from August through mid October, 1997), the solubility constraints indicate that $9,300 \mathrm{~kg}$ of the extracted carbon dioxide was generated by oxidation of organic contaminants. The two estimates agree to within $8 \%$ (Figure 25).

Using these constraints, we are able to evaluate the overall recovery achieved throughout the Visalia field during the first year of operations. The results, shown in Figure 26, reflect the overall shapes of the predicted removal vs. in situ destruction rates. Initial recovery rates are quite high, peak and diminish. As the field heats up, HPO begins, and continues at a fairly steady rate.

As of June, 1998, over 700,000 lbs of contaminant had been removed or destroyed; this accounts for about 95,000 gallons. About $16 \%$ of the total has been destroyed in situ via HPO. Air 
injection has increased HPO to $800 \mathrm{lb} /$ day from the fall average of about $300 \mathrm{lb} /$ day. Free product recovery is continuing slowly. Contaminant concentrations are dropping in the extraction wells; the site is cleaning from the periphery inward.

\section{Summary}

Through the Visalia field tests, HPO destruction has been confirmed in soil and groundwater at rates similar to those observed in the laboratory, under realistic field remediation conditions. HPO appears to work as fast as oxygen can be supplied, at rates similar to those measured in the laboratory. These results were obtained during a full-scale remediation, with commercial partners.

The predictive models used to design HPO steam injection systems have been validated by using conservative tracers to confirm mixing rates, oxygen consumption, carbon dioxide release, and effects of real-world heterogeneity. The key parameters necessary to optimize in situ destruction are understood

Field monitoring of the HPO process is possible. Using inert tracers, the injected fluids can be accurately identified and tracked. The fluid chemistry matched that observed in laboratory tests. Model simulations were verified in the field. Accurate field measurements of the critical fluid parameters (destruction chemistry, oxygen content, steam front location) have been demonstrated, using existing monitoring wells and portable data systems with minimal capital cost.

With respect to the Visalia Pole Yard cleanup, tremendous removal rates have been achieved. Over $900,000 \mathrm{lb}$ of contaminants were removed or destroyed in a little more than one year of operations. Previous recovery amounted to $10 \mathrm{lb} /$ week. HPO steadily destroys contaminants in situ; up to $800 \mathrm{lb}$ of PAH contaminants are being destroyed at Visalia by HPO each day. 


\section{Acknowledgements}

We gratefully acknowledge the support of the U.S. Department of Energy's Office of Environmental Restoration and Office of Science and Technology, and LLNL's Laboratory Directed Research and Development program. This work could not have been performed without the support of the Southern California Edison Co. and its Visalia Pole Yard employees, who cheerfully worked a 24-hour schedule in support of this experiment. SteamTech Environmental Services of Bakersfield, California, provided field support with steaming and temperature and ERT data. We are indebted to Allen Elsholz for his tireless operation and maintenance of all the field measuring systems and for his work with Ben Johnson and George Metzger in designing and constructing the down-hole scientific equipment.

Work performed under the auspices of the U.S. Department of Energy by the Lawrence Livermore National Laboratory under Contract W-7405-Eng-48. 


\section{References}

Aines, R.D.; Leif, F.; Knauss, K.; Newmark, R.L.; Chiarappa, M.; Davison, M.L.; Hudson, G.B., Weidner, R.; and Eaker, C.; Tracking inorganic carbon compounds to quantify in situ oxidation of polycyclic aromatic hydrocarbons during the Visalia Pole Yard hydrous pyrolysis/oxidation field test, 1998 (in prep).

Cummings, Mark A.; Visalia Steam Remediation Project: Case Study of an Integrated Approach to DNAPL Remediation. Los Alamos National Laboratory Report, LA-UR-9704999; 1997; 9 pp.

Dolfing J. and Janssen D. B. Estimates of Gibbs free energies of formation of chlorinated aliphatic hydrocarbons. Biodegradation 5, 1994; 21-28.

Ferguson, Jane A.; Newmark, Robin L.; Richards, James; Henshaw, John M.; Walt, David R.; A Fiber Optic Oxygen Sensor for Chemical and Bioprocess Monitoring (in prep).

Geraghty; Miller; Remedial Investigation/Feasibility Study, Southern California Edison, Visalia Pole Yard, Visalia, CA, Southern California Edison Co., 1992.

Kana T.M., Darkangelo, C; Hunt, M.D., Oldham, J.B.; Membrane Inlet Mass Spectometer For Rapid Hight Precision Determination of N-2, O-2 and Ar in Environmental Water Samples, Analytical Chemistry, 1994 Dec 1, v66, N23:4166-4170.

Knauss, Kevin G.; Aines, Roger D.; Dibley, Michael J.; Leif, Roald N.; Mew, Daniel A.; Hydrous Pyrolysis/Oxidation: In-Ground Thermal Destruction of Organic Contaminants. . Lawrence Livermore National Laboratory, Report, UCRL-JC 126636, 1997; 18 pp.

Knauss, Kevin G.; Dibley, Michael J.; Leif, Roald N.; Mew, Daniel A.; Aines, Roger D. "Aqueous Oxidation of Trichloroethene (TCE): A Kinetic and Thermodynamic Analysis". In Physical, Chemical and Thermal Technologies, Remediation of Chlorinated and Recalcitrant Compunds, Proceeding of the First International Conference on Remediation of Chlorinated and Recalcitrant Compounds; Wickramanayake, G.B., Hinchee, R.E., Eds.; Battelle Press, Columbus, OH, 1998a; pp359-364.

Also available as Lawrence Livermore National Laboratory, Report, UCRL-JC-129932, 1998; 8 pp.

Knauss, Kevin G.; Dibley, Michael J.; Leif, Roald N.; Mew, Daniel A.; Aines, Roger D. "Aqueous Oxidation of Trichloroethene (TCE): A Kinetic analysis." Accepted for Publication, Applied Geochemistry; 1998b.

Knauss, Kevin G.; Dibley, Michael J.; Leif, Roald N.; Mew, Daniel A.; Aines, Roger D. "Aqueous Oxidation of Trichloroethene (TCE) and Tetrachloroethene (PCE) as a Function of Temperature and Calculated Thermodynanmic Quantities, Submitted to Applied Geochemistry; 1998c. 
Leif, Roald N.; Chiarrappa, Marina; Aines, Roger D.; Newmark Robin L.; and Knauss, Kevin G. "In Situ Hydrothermal Oxidative Destruction of DNAPLS in a Creosote Contaminated Site." In Physical, Chemical and Thermal Technologies, Remediation of Chlorinated and Recalcitrant Compunds, Proceeding of the First International Conference on Remediation of Chlorinated and Recalcitrant Compounds; Wickramanayake, G.B., Hinchee, R.E., Eds.; Battelle Press, Columbus, OH, 1998; pp 133-138.

Also available as Lawrence Livermore National Laboratory, Report, UCRL-JC-129933, 1998; 8 pp.

Leif, Roald N.; Aines, Roger D.; Knauss, Kevin G. Hydrous Pyrolysis of Pole Treating Chemicals: A) Initial Measurment of Hydrous Pyrolysis Rates for Napthalene and

Pentachlorophenol; B) Solubility of Flourene at Temperatures Up To $150^{\circ} \mathrm{C}$; Lawrence Livermore National Laboratory, Report, UCRL-CR-129938, 1997a; 32pp.

Leif, Roald N.; Knauss, Kevin G.; Mew, Daniel A.; Aines, Roger D. Destruction of 2,2 ',3Trichlorobiphenyl in Aqueous Solution by Hydrous Pyrolysis / Oxidation (HPO). Lawrence Livermore National Laboratory, Report, UCRL-ID 129837, 1997b; 21 pp.

Newmark, Robin L.; Aines, Roger D.; Dumping Pump and Treat: Rapid Cleanups Using Thermal Technology. Lawrence Livermore National Laboratory, Report, UCRL-JC 126637, 1997; 23 pp.

Peurrung, Loni M., Bergsmann, Theresa M.; Powell, Thomas D., Roberts, Janet S.; Schalla, Robert "Six-Phase Soil Heating of the Saturated Zone". In Physical, Chemical and Thermal Technologies, Remediation of Chlorinated and Recalcitrant Compunds, Proceeding of the First International Conference on Remediation of Chlorinated and Recalfitrant Compounds;

Wickramanayake, G.B., Hinchee, R.E., Eds.; Battelle Press, Columbus, OH, 1998; pp 63-68.

Udell, Kent S; Itamura, Michael T.; "Removal of Dissolved Solvents From Heated Heterogeous Soils During Depressurinzation." In Physical, Chemical and Thermal Technologies, Remediation of Chlorinated and Recalcitrant Compunds, Proceeding of the First International Conference on Remediation of Chlorinated and Recalfitrant Compounds; Wickramanayake, G.B., Hinchee, R.E., Eds.; Battelle Press, Columbus, OH, 1998; pp 57-62. 


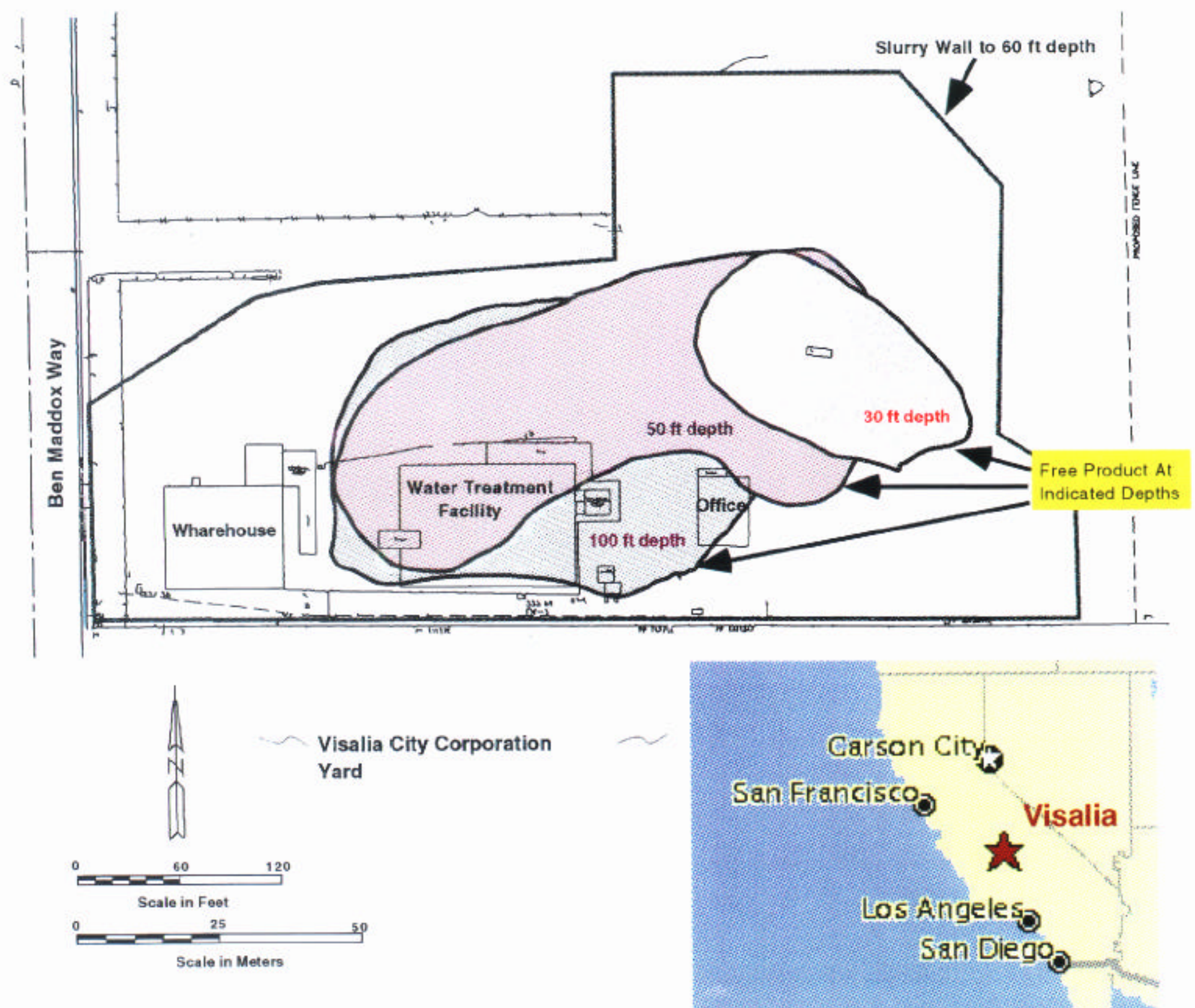

Figure 1: Site map, showing the location of the Visalia Pole Yard. Contours indicate the lateral extent of free product contamination at depth (Geraghty and Miller, 1992, Weidner, pers. comm.) 


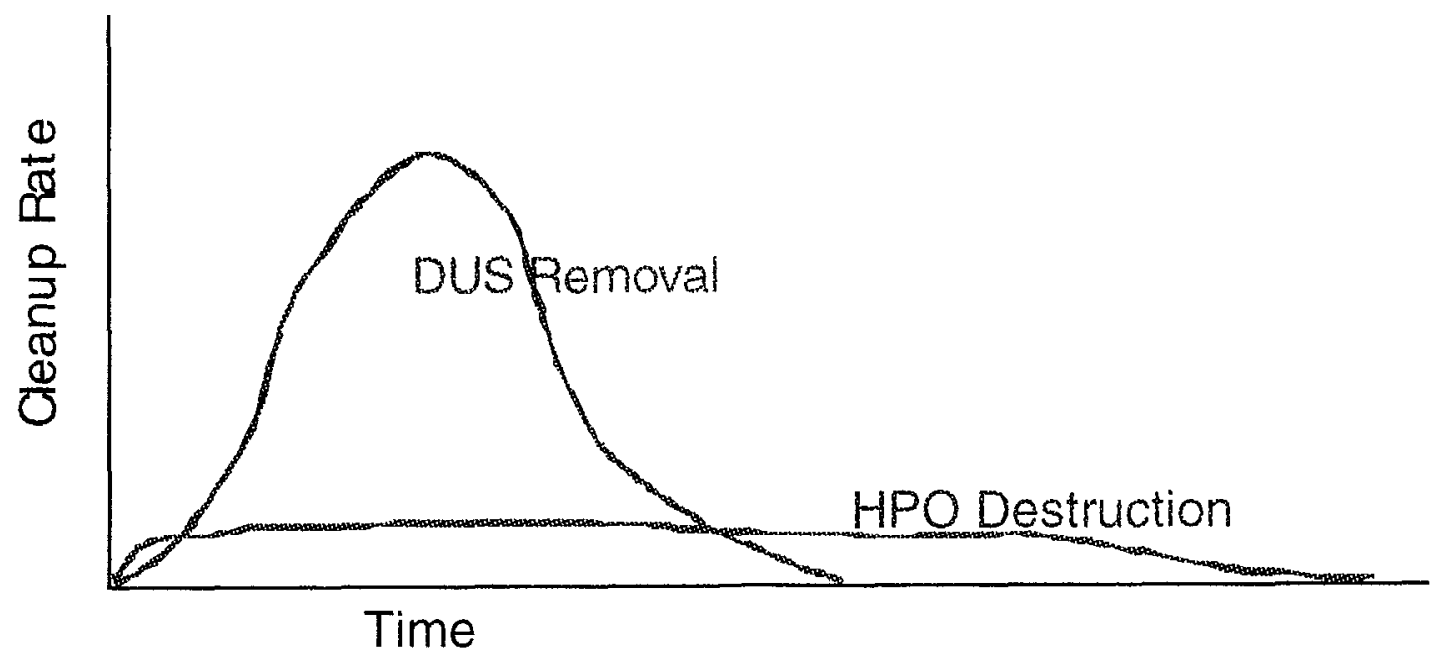

Figure 2. DUS and HPO concept: removal and destruction work together. DUS mobilizes contaminants for rapid removal. HPO destroys organics in situ. 


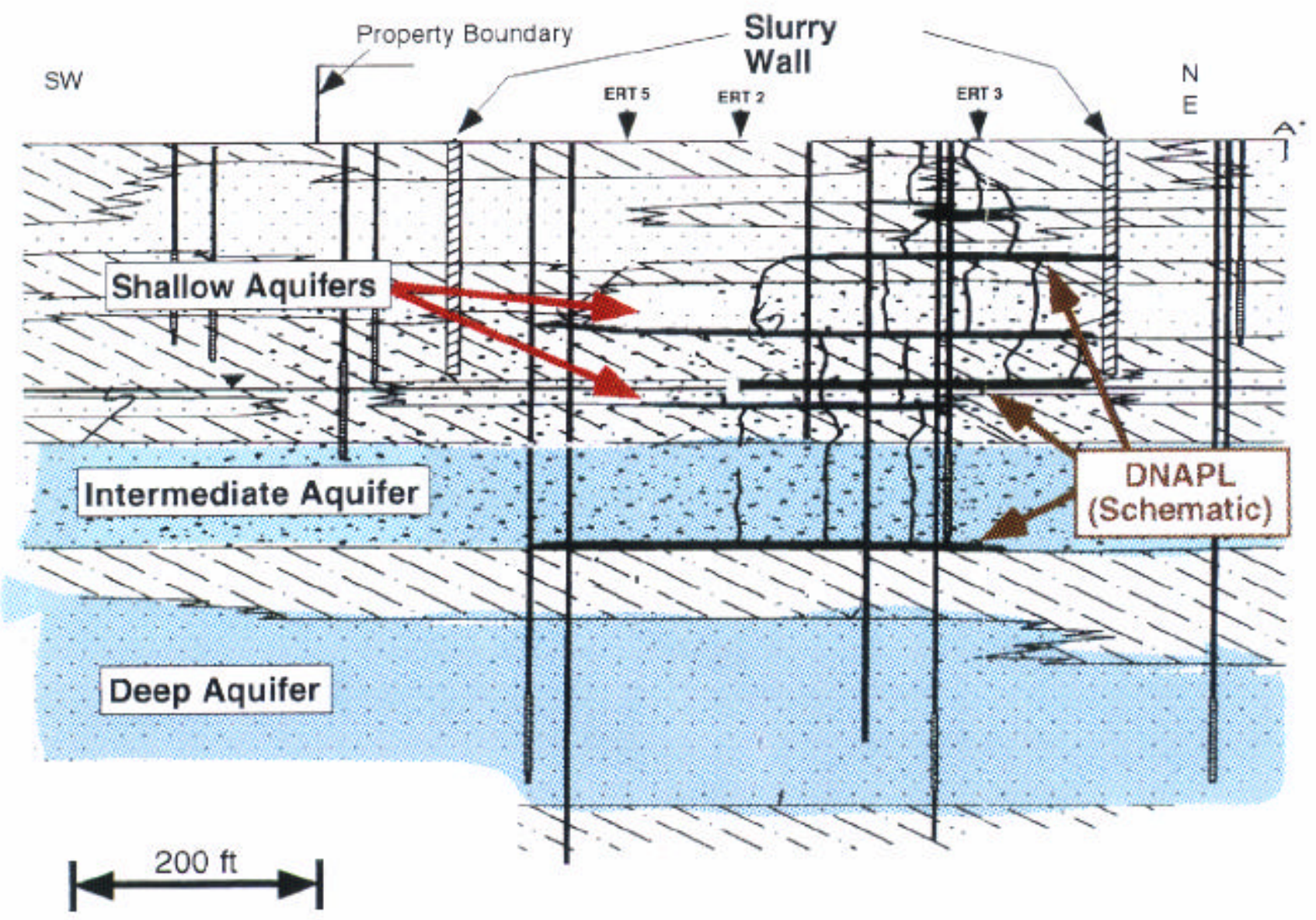

Figure 3. Cross section (approximately northeast-southwest) through the Visalia site, showing the original status of DNAPL contaminant and approximate lithology (Geraghty and Miller, 1992). Depth to water is about $60 \mathrm{ft}$ today (the shallow aquifers are unsaturated). Drinking water is produced from the uncontaminated deep aquifer. 


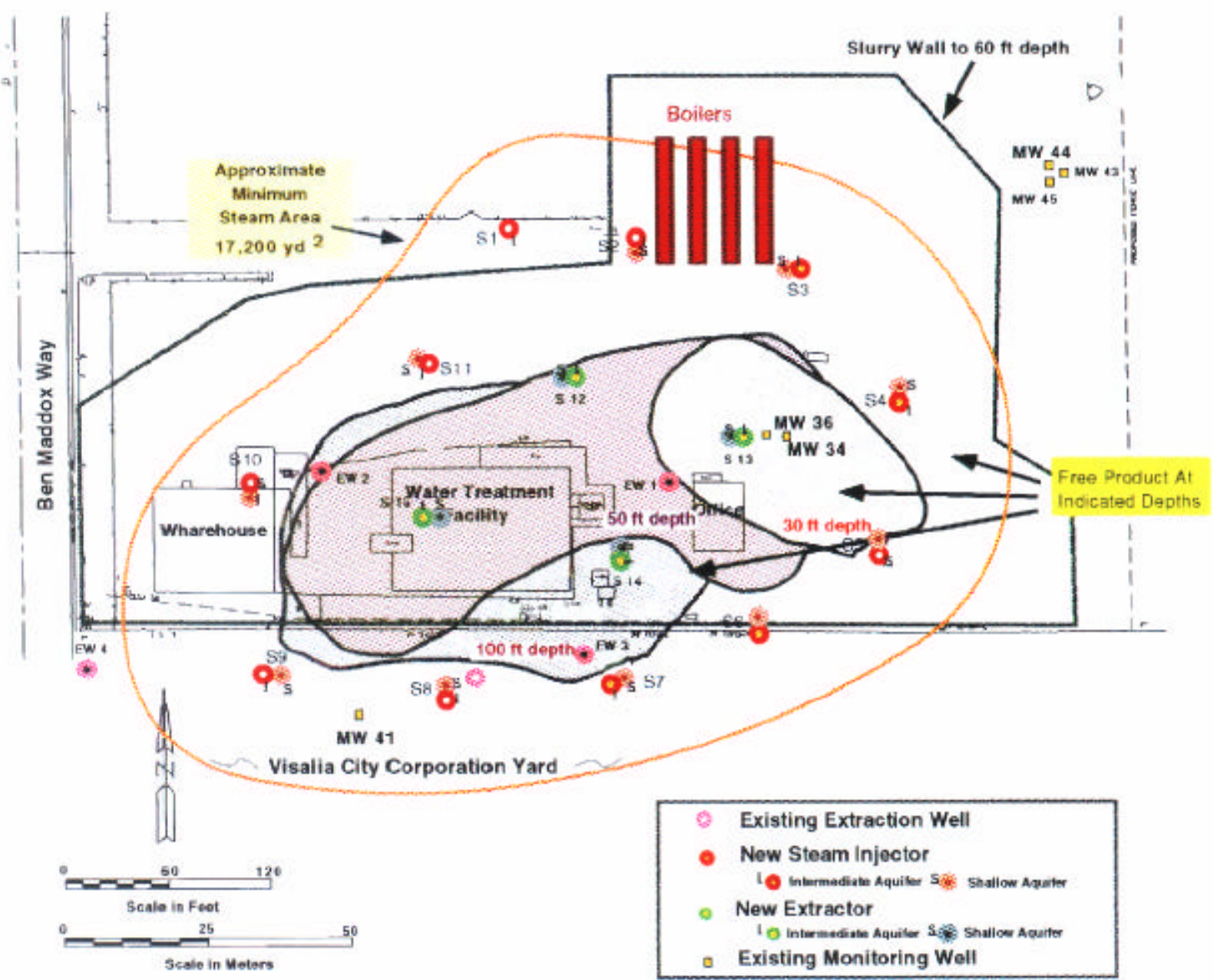

Figure 4: Operational well layout for the Visalia Pole Yard thermal remediation. 


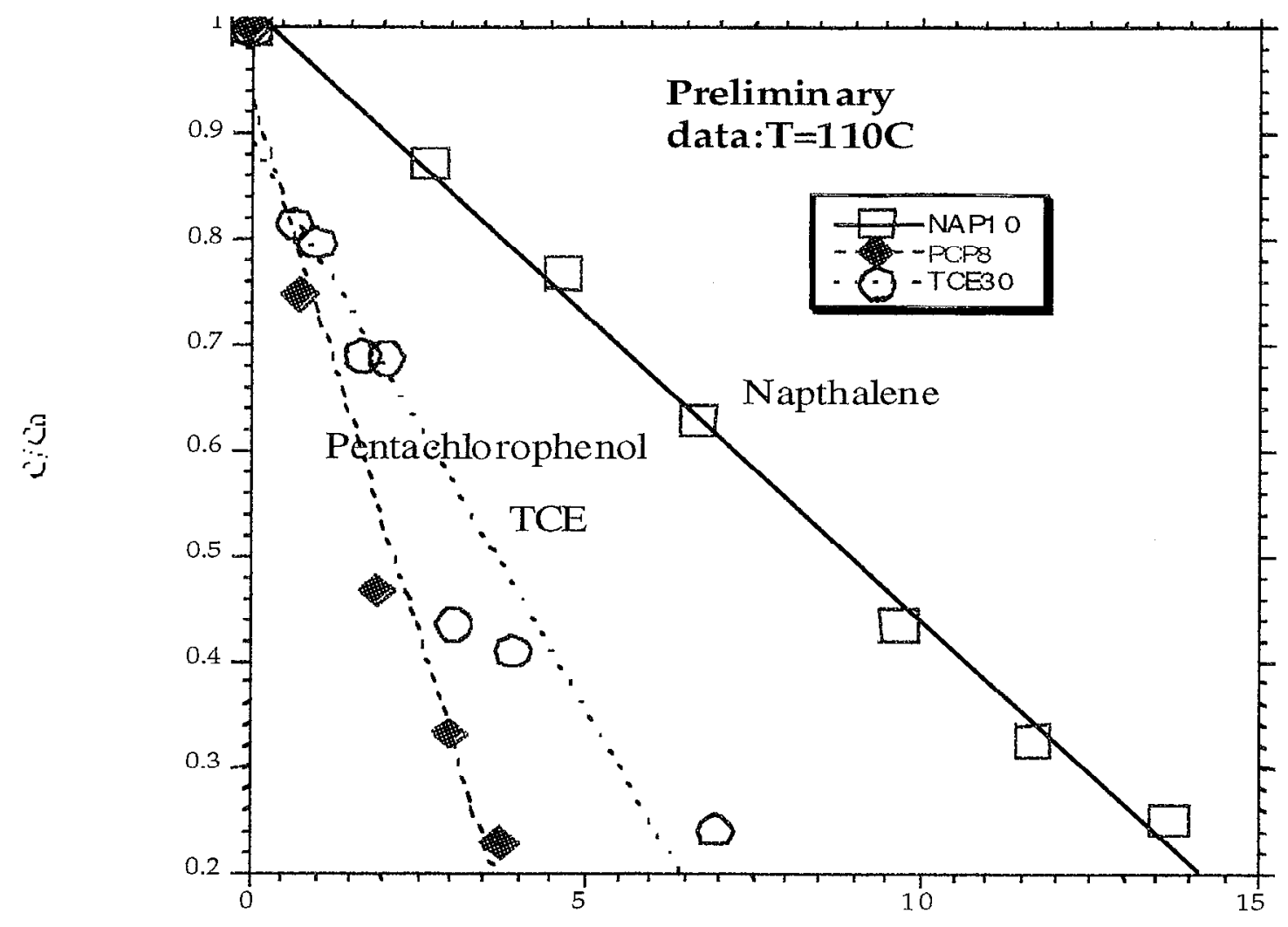

Tine (d)

Figure 5. Preliminary comparison of the rate of destruction of pentachlorophenol, TCE, and naphthalene under similar conditions. The majority of other Visalia contaminants were expected to fall within this general range. 


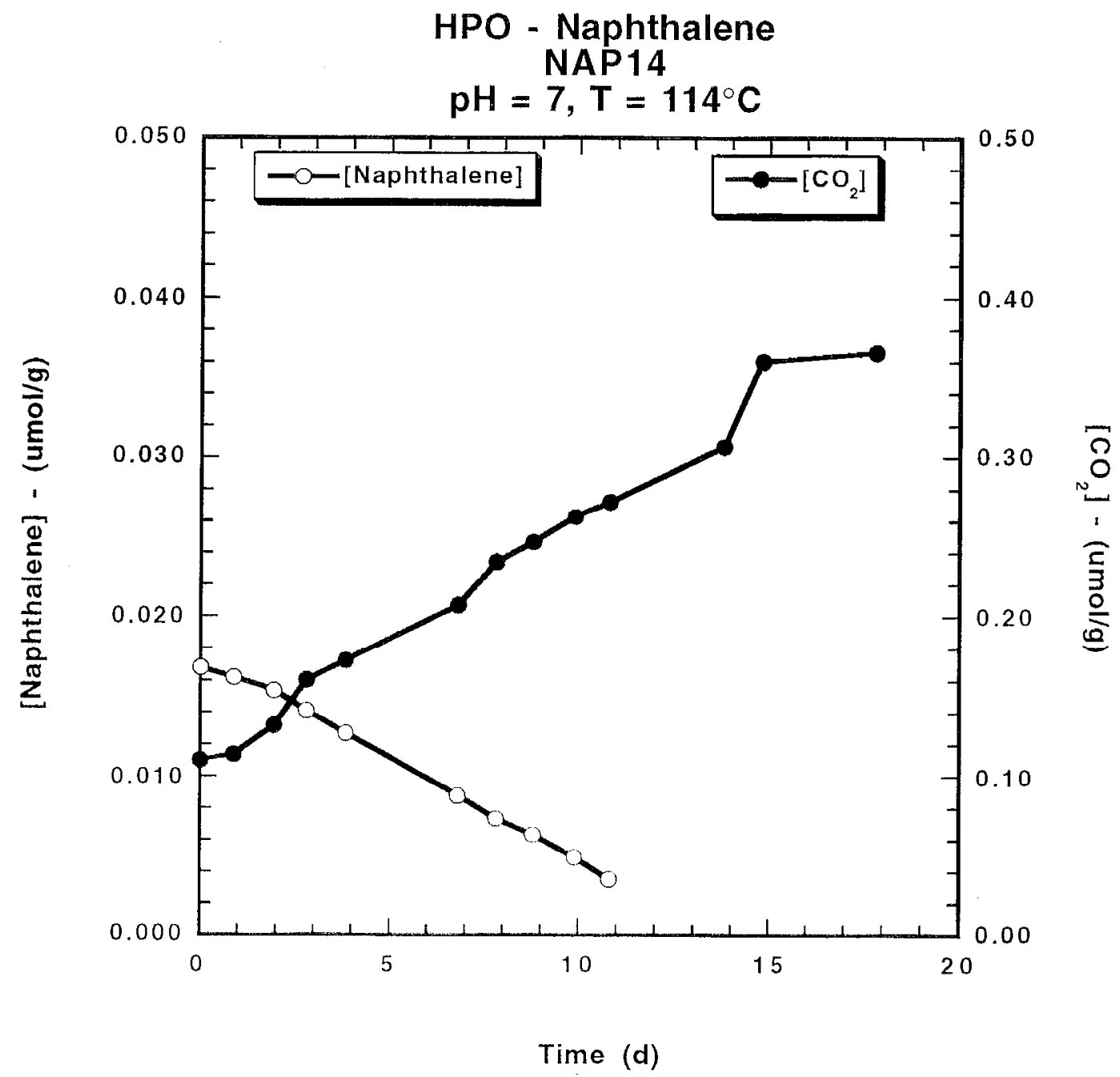

Figure 6: Naphthalene destruction and carbon dioxide production during HPO experiment NAP14 $\left(114^{\circ} \mathrm{C}\right)$ (from Leif et al., 1998). 


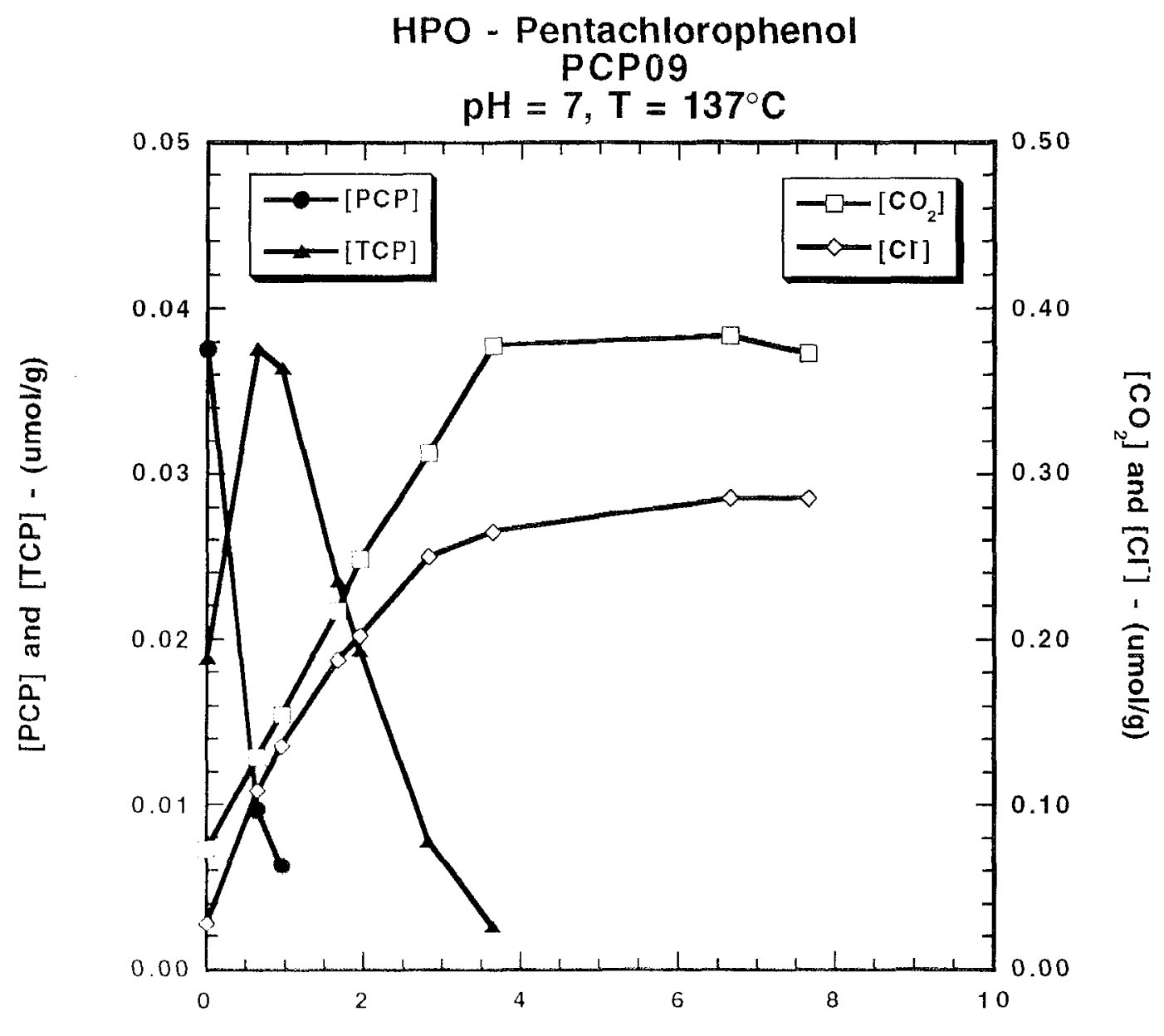

Time (d)

Figure 7: Concentrations of pentachlorophenol, 2,3,5,6-tetrachlorophenol, carbon dioxide and chloride ion during IIPO experiment PCP09 $\left(137^{\circ} \mathrm{C}\right)$ (from Leif et al., 1998). 


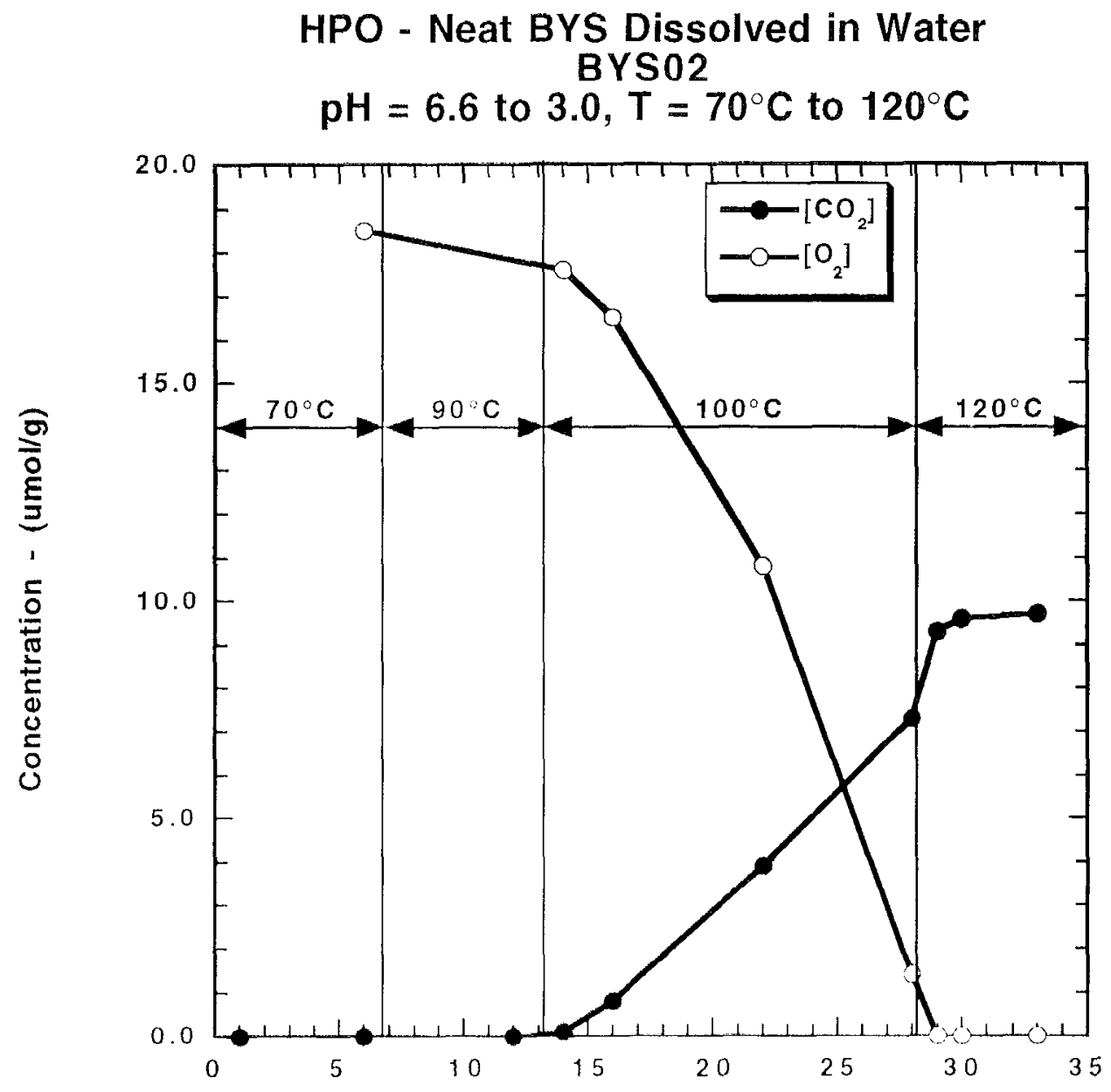

Time (d)

Figure 8: Oxygen consumption and carbon dioxide production during oxidation of pole tar (Polycyclic Aromatic Hydrocarbons) dissolved in water, conducted in a Dickson autoclave. Neat BYS dissolved in water is oxidized as it is heated to temperatures ranging from $70^{\circ} \mathrm{C}$ to $120^{\prime \prime} \mathrm{C}$ (from Leif et al., 1998). 


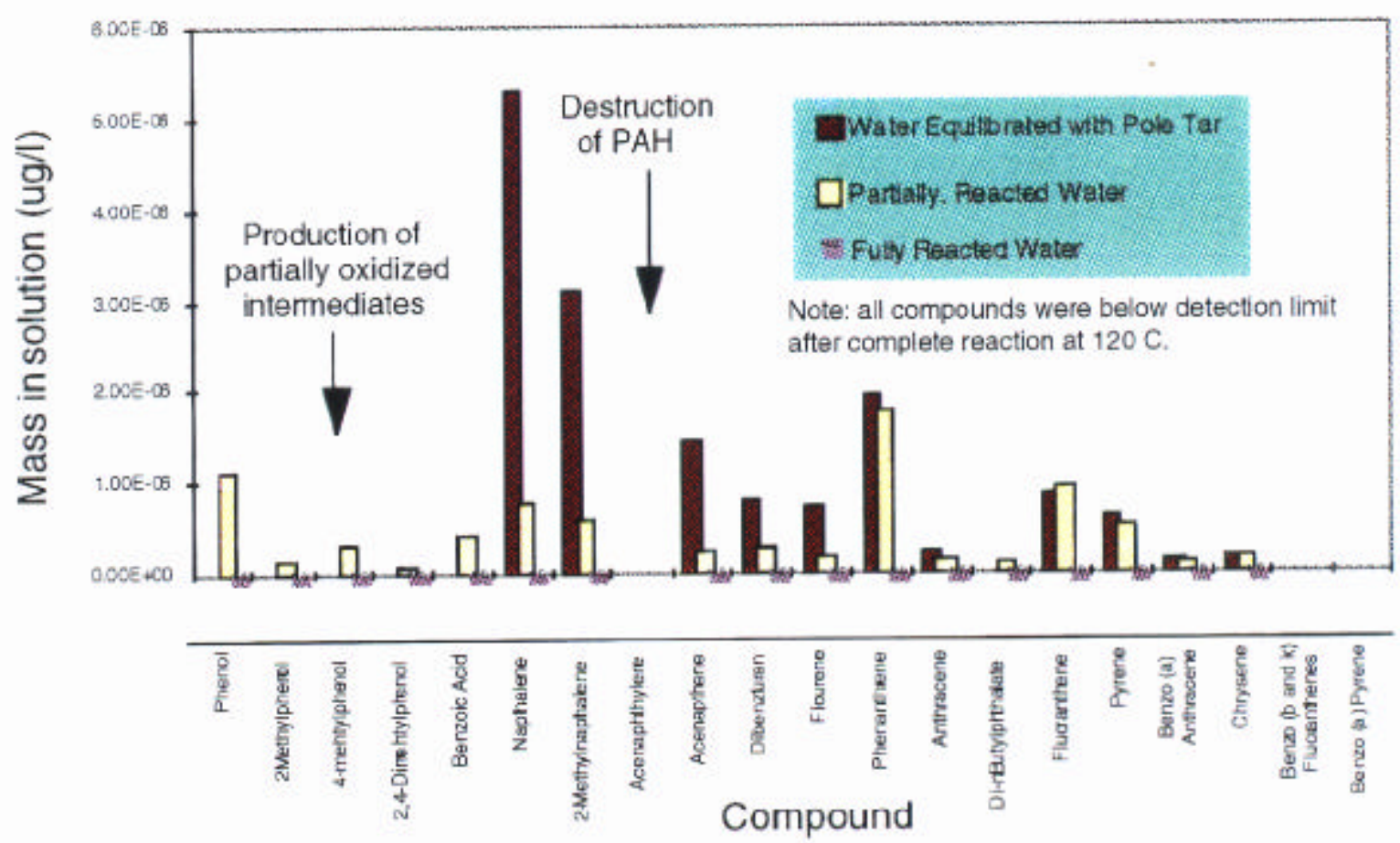

PAH compunds in pole tar tests, measured by EPA met hod 827 OA.

Figure 9. Water equilibrated with Visalia free product was initially heated in the presence of insufficient oxygen for complete oxidation (partially reacted water results). Then, the experiment was allowed to continue with sufficient oxygen to fully oxidize all the compounds (fully reacted water results). 


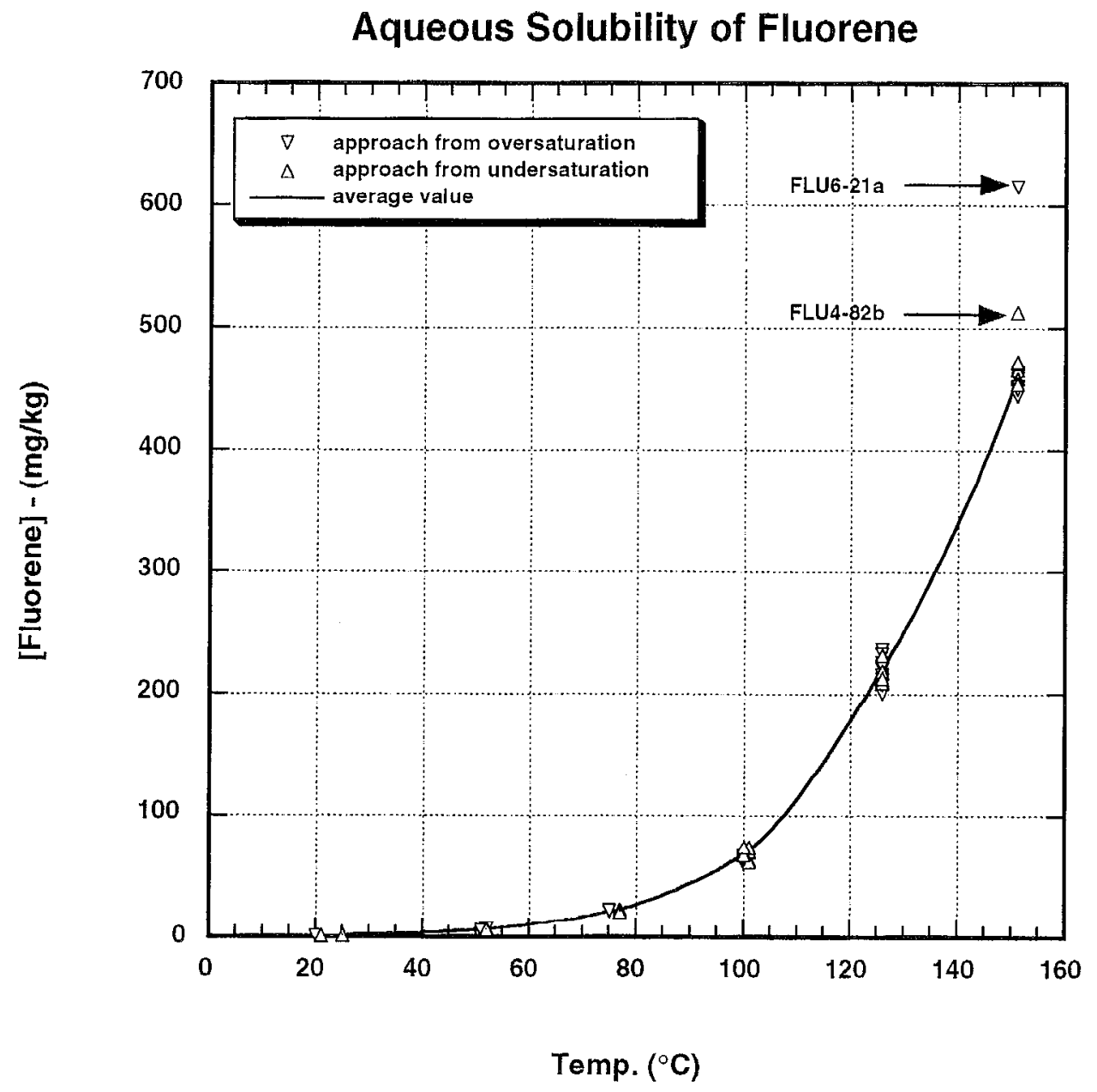

Figure 10: Aqueous solubility measurements of fluorene vs. temperature (from Leif et al., 1998) 


\section{Packer/Pump System}

To Treatment

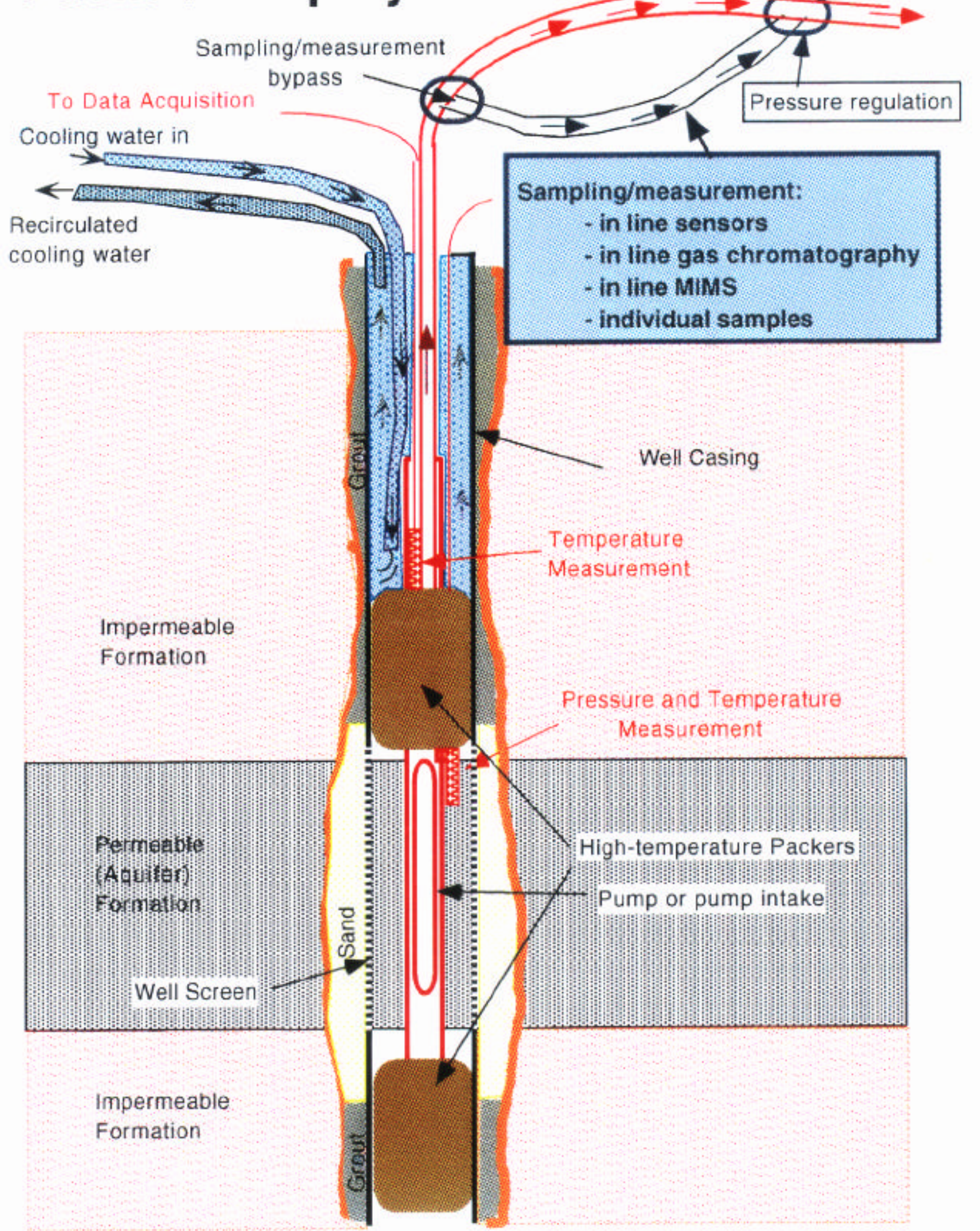

Figure 11: Pump/packer system schematic 


\section{Packer System Measurements and Sampling}

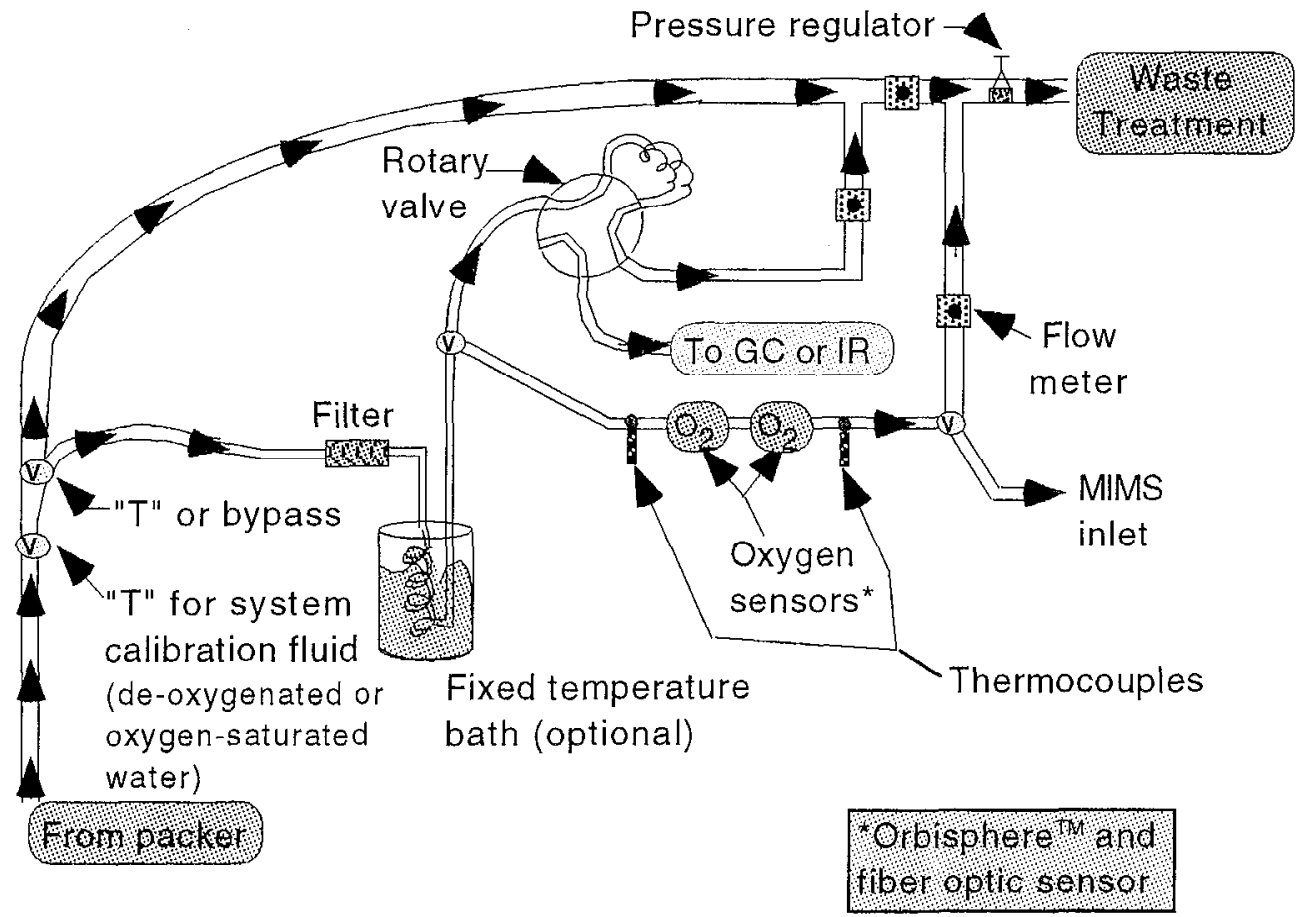

Figure 12: Schematic of the measurement and sampling system. 
First Steam Pass Temperatures

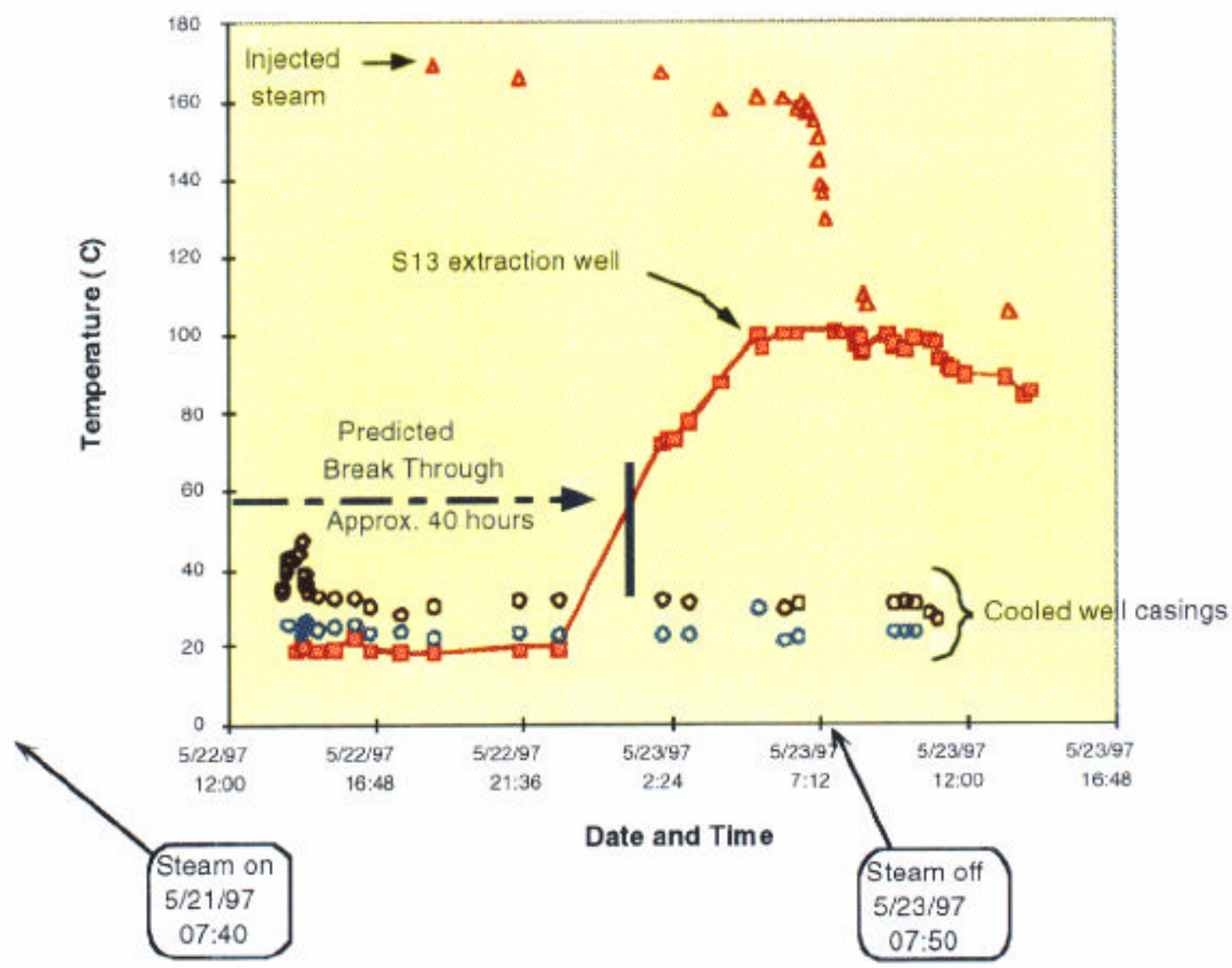

Figure 13. Temperature measurements made in the $\$ 13$ extraction well show rapid rise on steam breakthrough, which occurred about 40 hours after injection began, as predicted by the NUFT models. Temperatures in the protected plastic monitoring well casings remained low. 

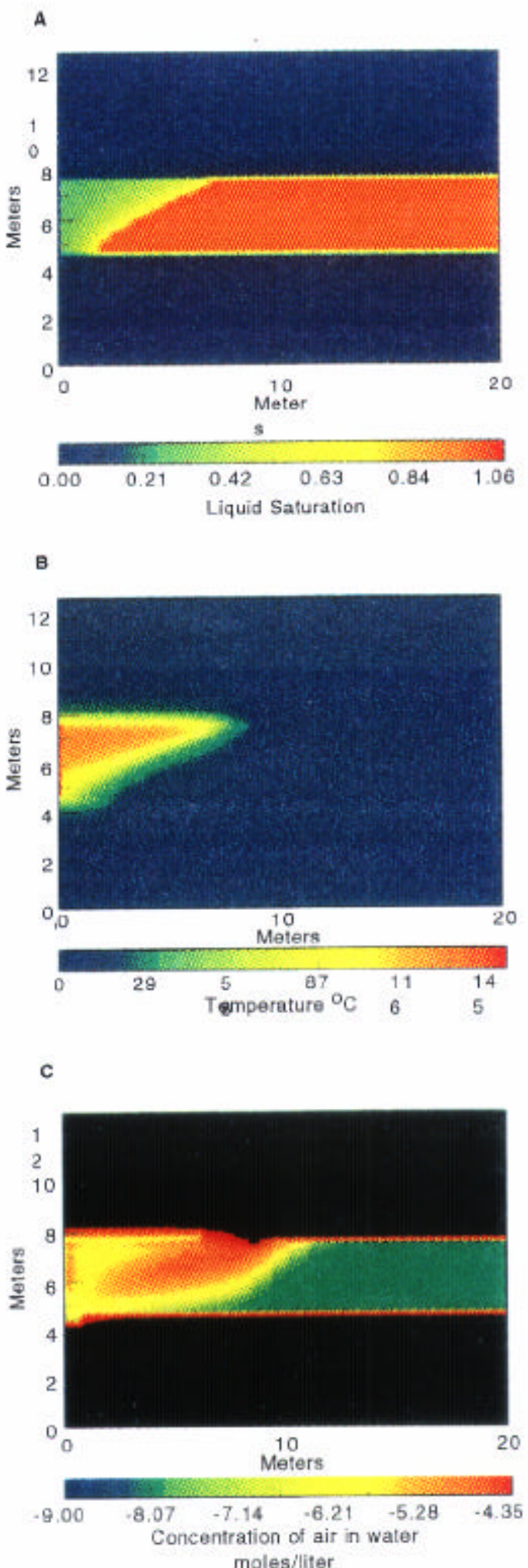

Figure 14. Simulation results for injection of steam and supplemental air. See text for explanation. 

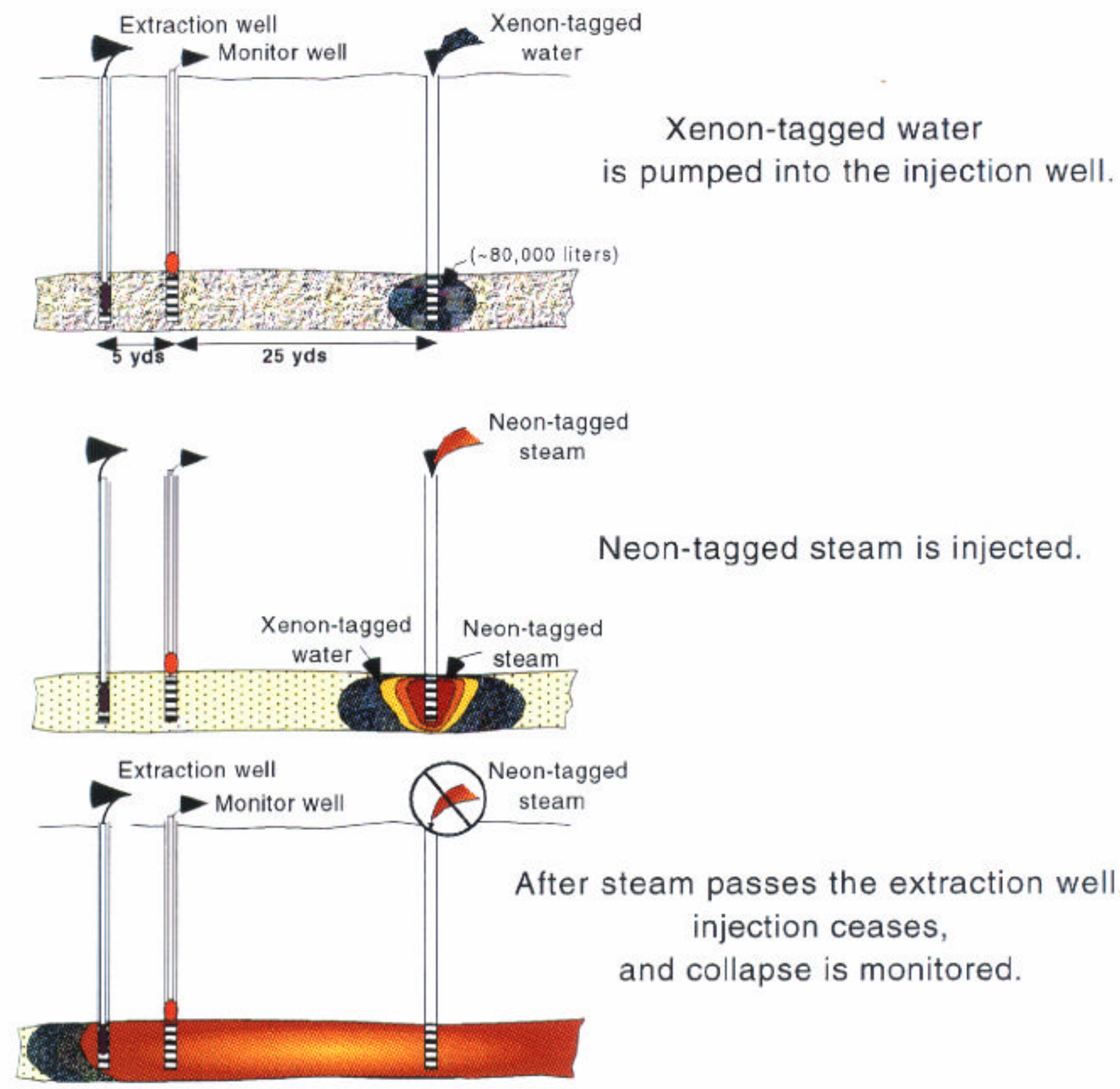
injection ceases, and collapse is monitored.

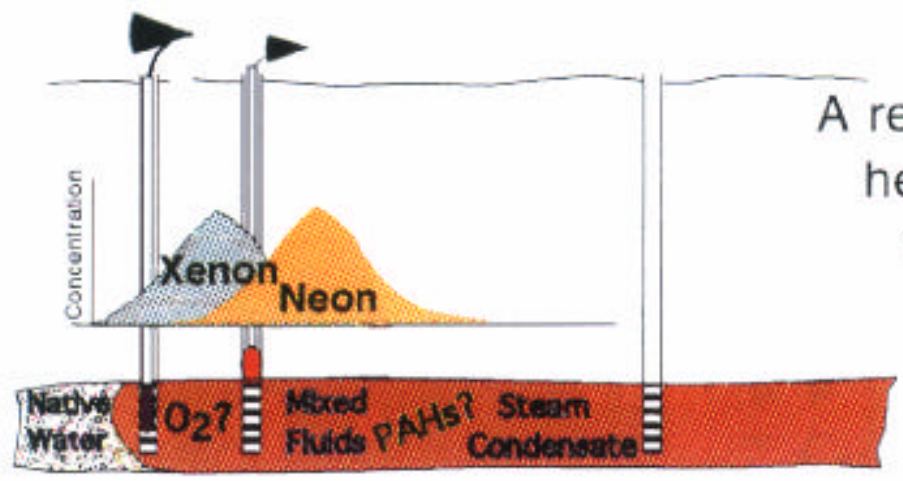

Figure 15: Conceptual design for the first tracer experiment. 


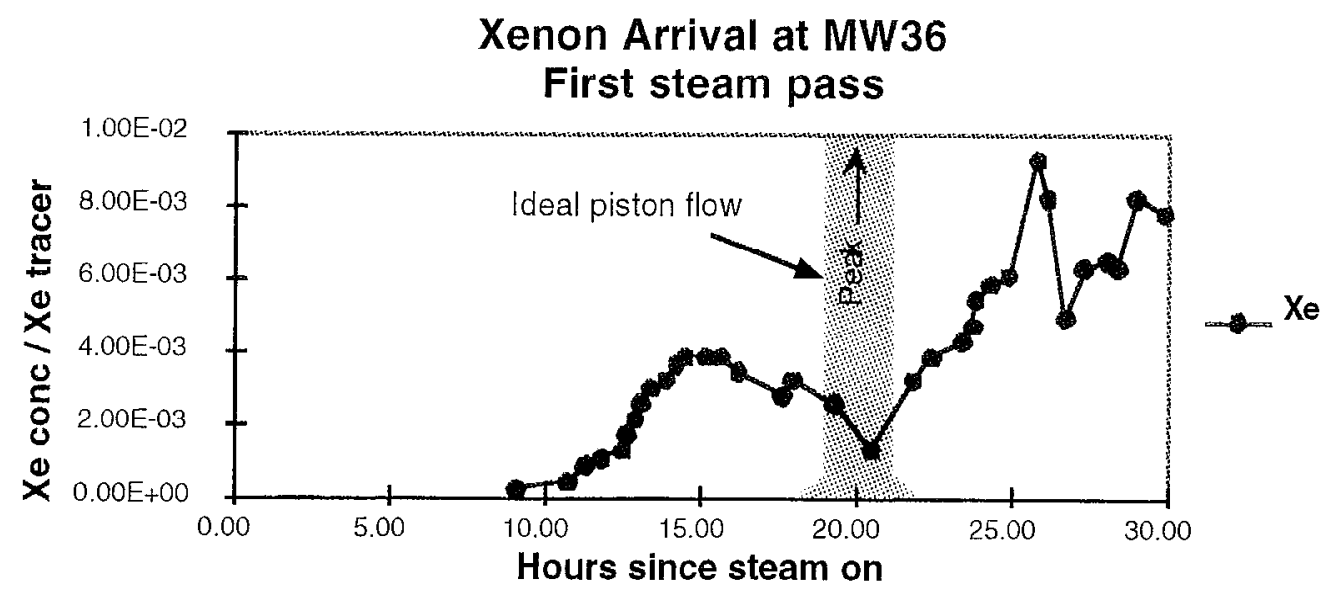

Figure 16. Xenon arrival at MW36 during the first tracer experiment indicates extensive mixing and dispersion within the aquifer. Xenon concentrations rose gradually over a period of approximately 30 hours. The drop in concentration from 15-20 hours occurred during a drop in injection pressure; a mini-collapse of the steam zone permitted the steam front to first approach the monitoring well, then recede from it. After injection pressure was restored, the steam front approached, then passed the monitoring well. If pure piston-flow displacement occurred, xenon would be expected to arrive during an approximately 2 -hour window, with peak concentrations many times those observed (shaded zone). 
Leading edge fluid source composition

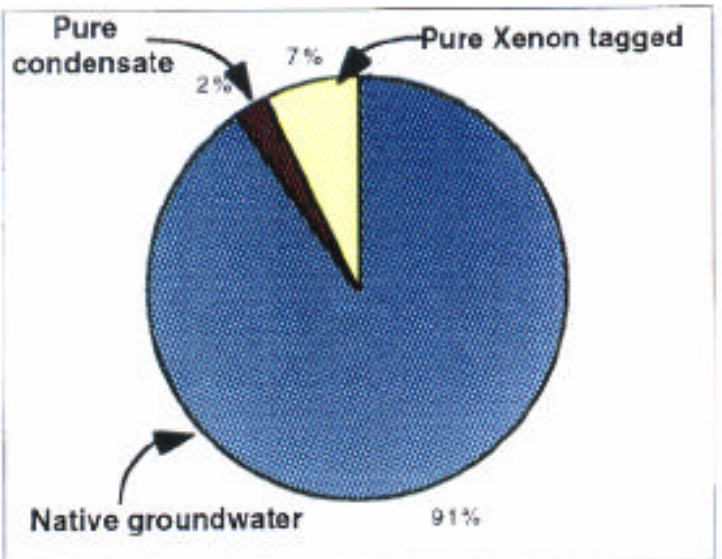

Reaction zone fluid source composition

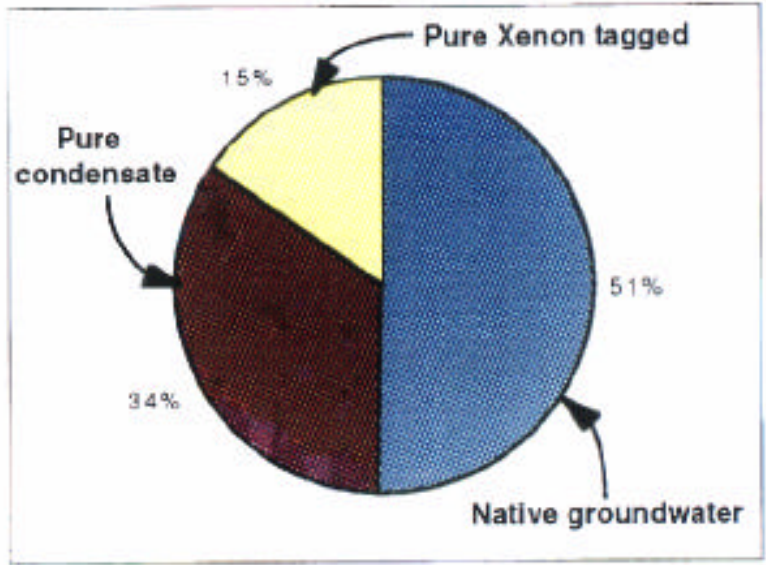

Figure 17. Tracers permit the identification of the fluid sample source composition. 


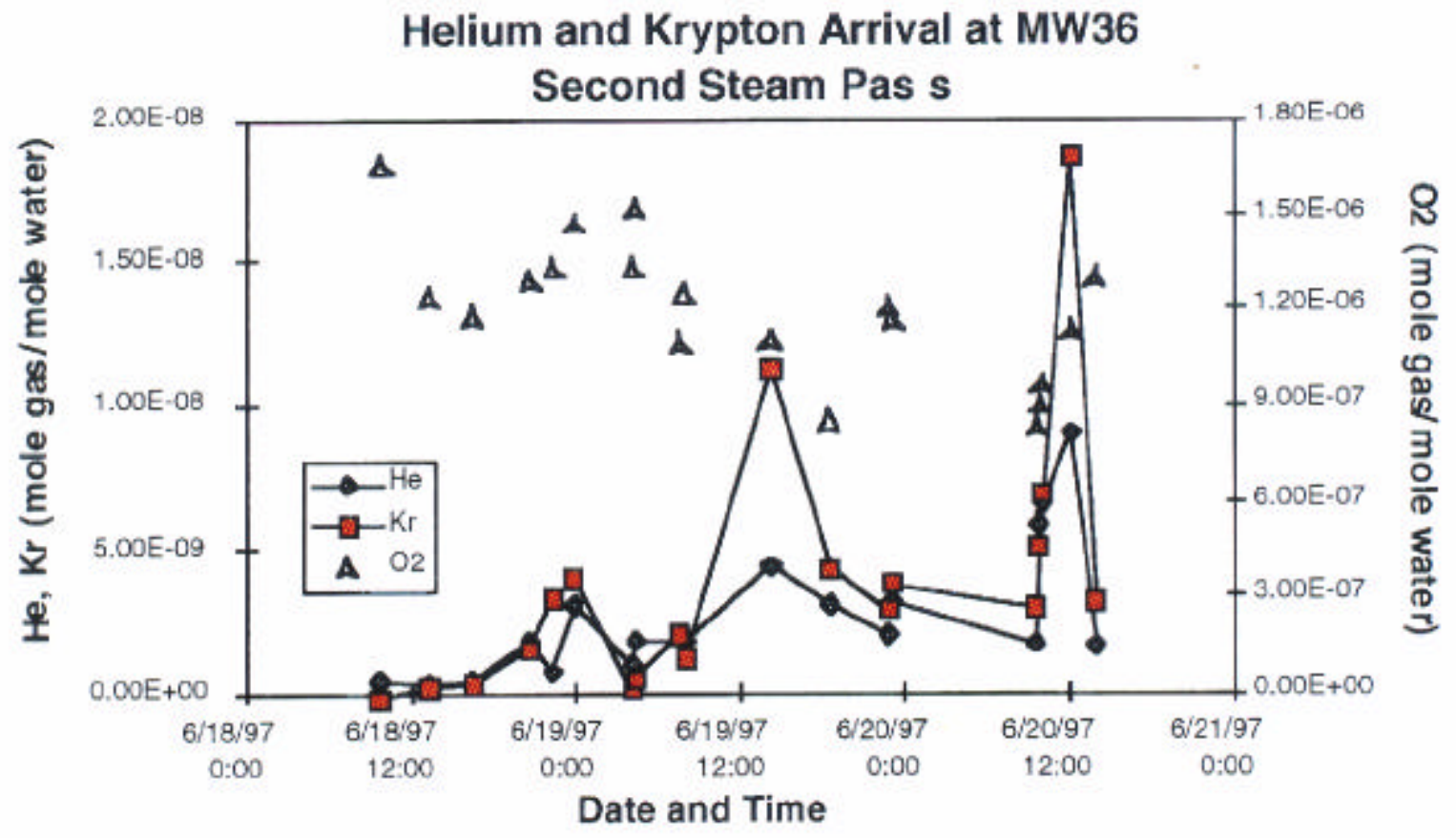

Figure 18. Helium and krypton arrival at MW36 during the second tracer experiment. Gradual increase in concentrations support continued mixing and dispersion. Decreasing dissolved oxygen reflects the oxidation reactions consuming oxygen as it contacts contaminated fluids. 


\section{Oxygen Depletion During Experiments}

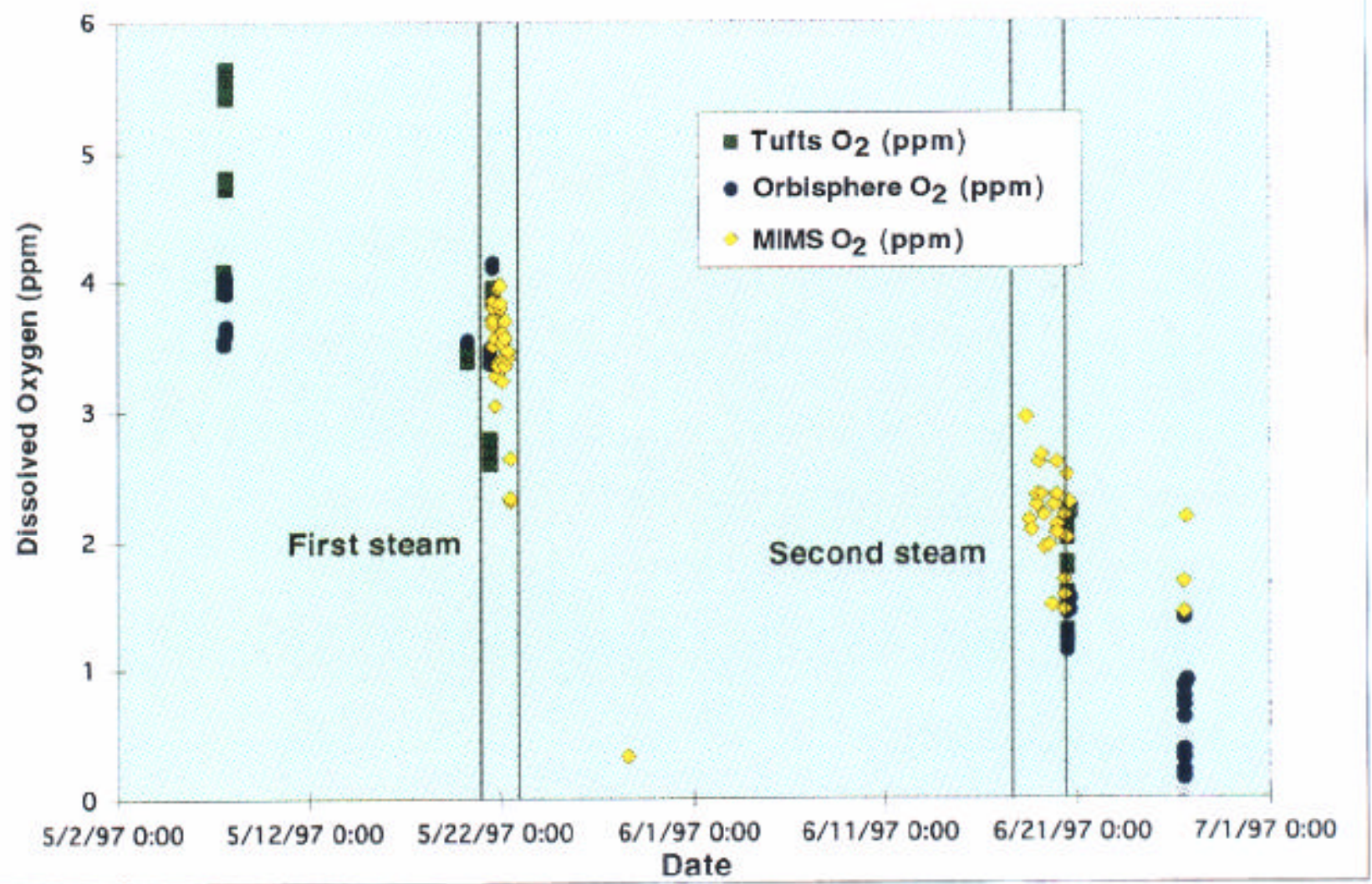

Figure 19. Dissolved oxygen measured in MW36 during the field experiments. Measurements were made using three different methods; an experimental fiber optic sensor developed by Tufts University (Tufts), a commercially-available sensor (Orbisphere), and the Membrane Inlet Mass Spectrometer (MIMS). 


\section{Increases in oxidized BYS constituent}
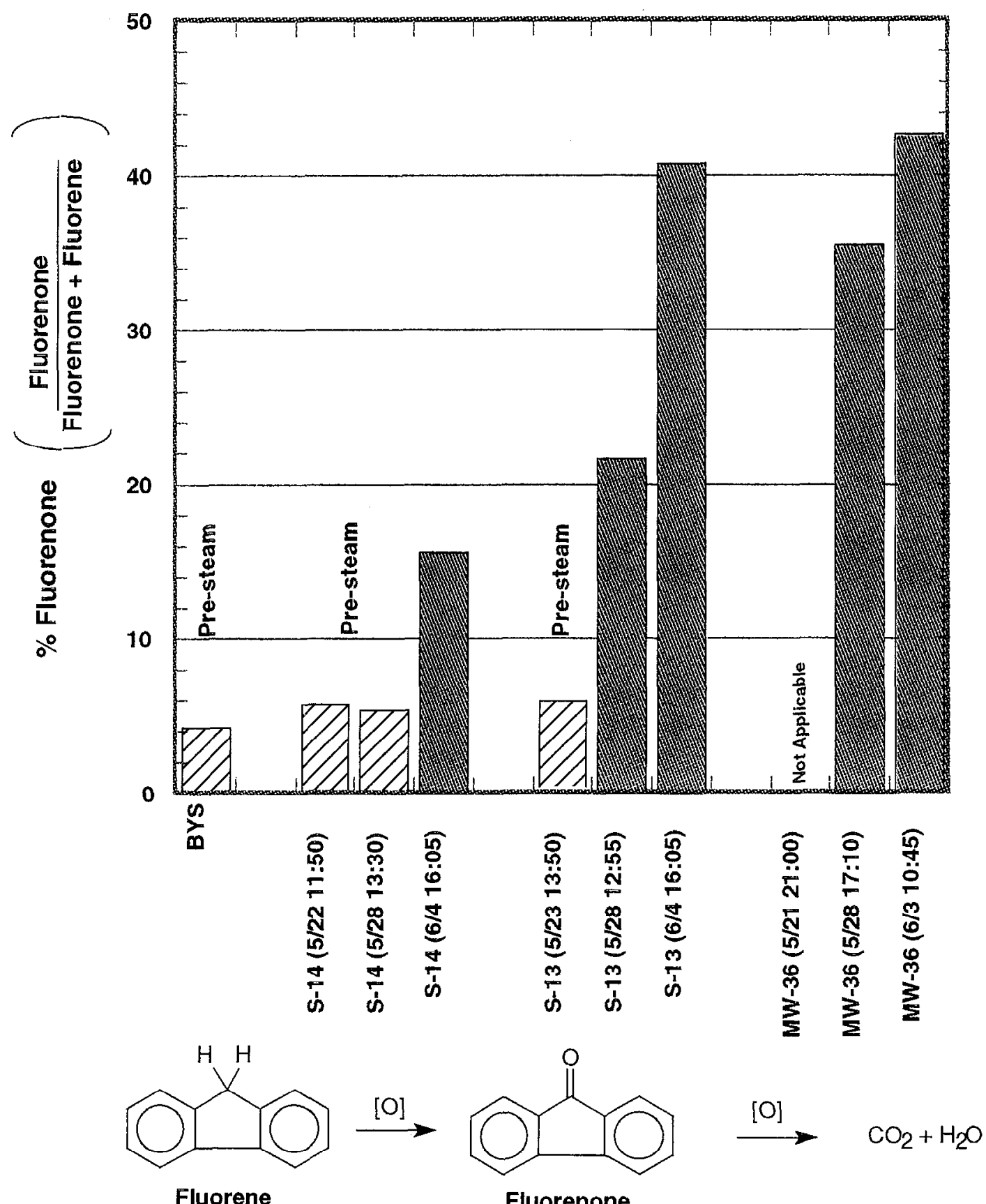

Figure 20: Ratio of Fluorenone to (Fluorenone + Fluorene) in groundwater recovered before and after thermal treatment. Pre-steam ratios are shown with a hatched pattern. Values obtained after thermal treatment are shown as solid bars. 


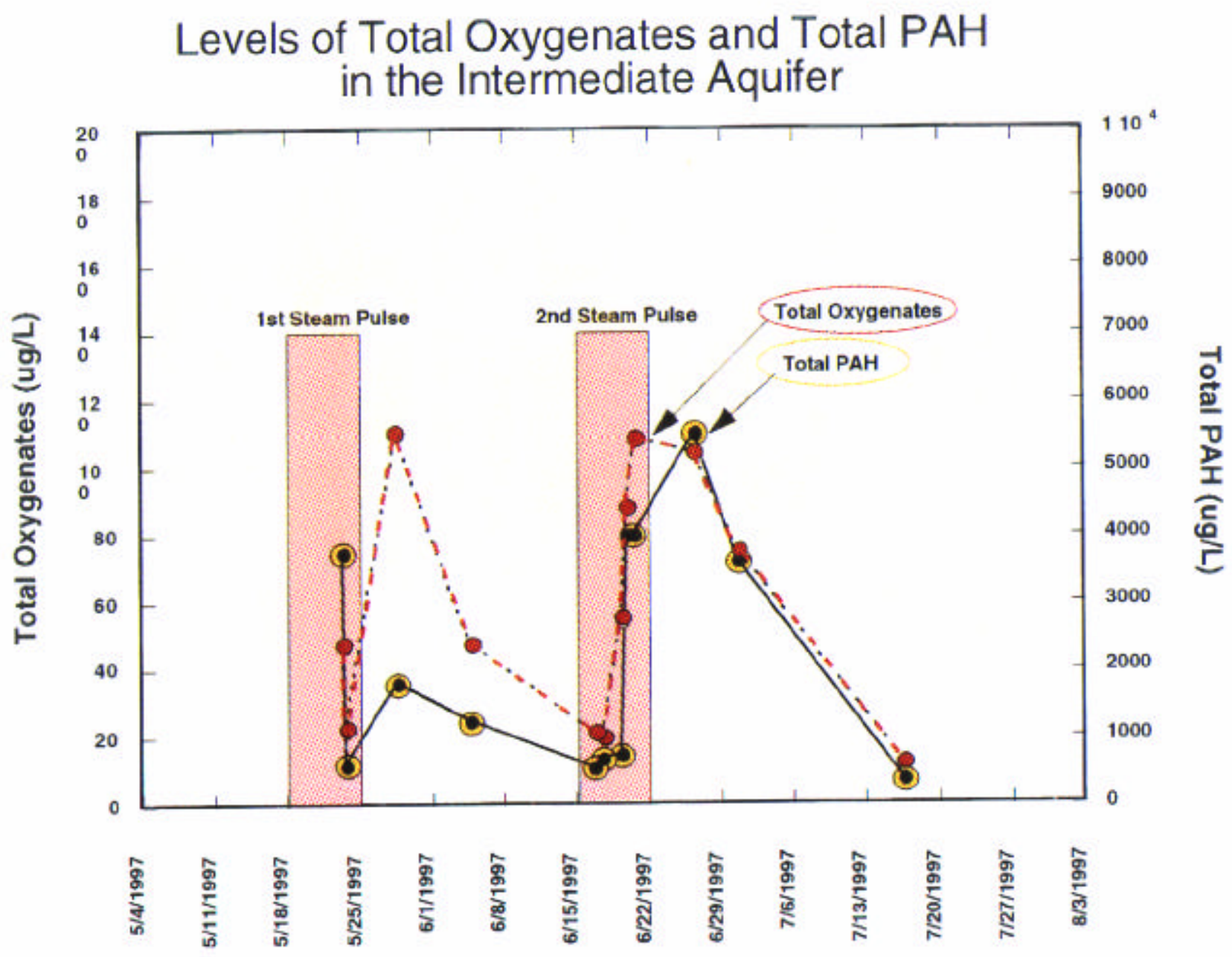

Figure 21. Total oxygenates and PAH detected in MW36 EPA Method 8270C), measured during and after steam injection through hexane extraction and by solid phase reaction, and abundance of oxidate intermediates. Both contaminant concentrations and oxidate intermediates increase immediately after steam collapse. Elevated PAH concentrations reflect enhanced mobilization due to DUS. Oxygenate increases are consistent with partial hydrocarbon oxidation by HPO. 
Temperature, ${ }^{\circ} \mathrm{C}$

Generalized

Lithology
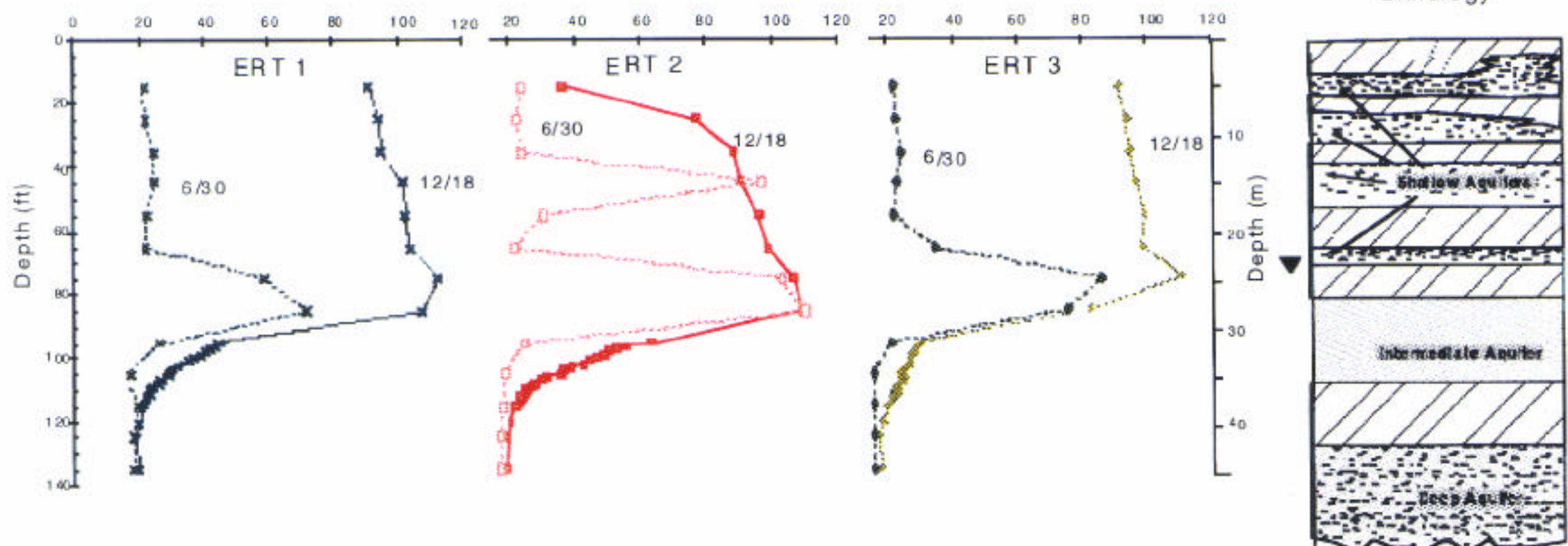

Figure 22. Temperature profiles show initial steam penetration into the more permeable units $(6 / 30 / 97)$, followed by uniform heating of the soil column from $95 \mathrm{ft}$ to the surface $(12 / 18 / 97)$. 


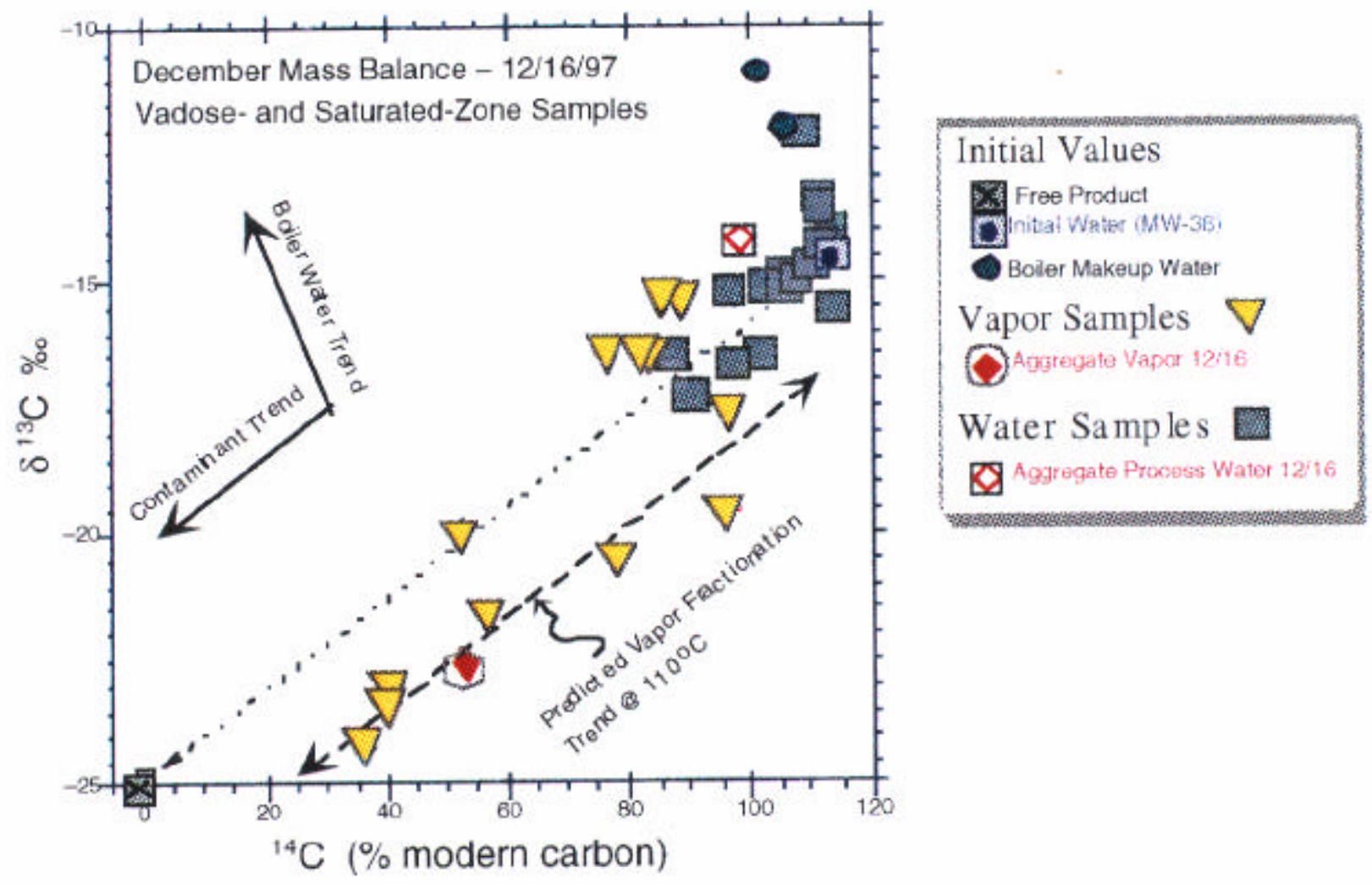

Figure 23. Carbon isotopic signature of Visalia water and vapor samples measured after steam injection began fall between that of background water (upper right) and that of free-product contaminant (lower left), revealing the influence of contaminant combustion. Aggregate vapor value indicates the signature of vapor entering the treatment plant on 12/16/97 (combined effluent from all extraction wells). The aggregate process water on the same day is also shown. The carbon values are corrected for atmospheric carbon (330 ppm $\mathrm{CO}_{2} 114$ pmc-14.5 $\left.\partial \mathrm{C} 13\right)$. 


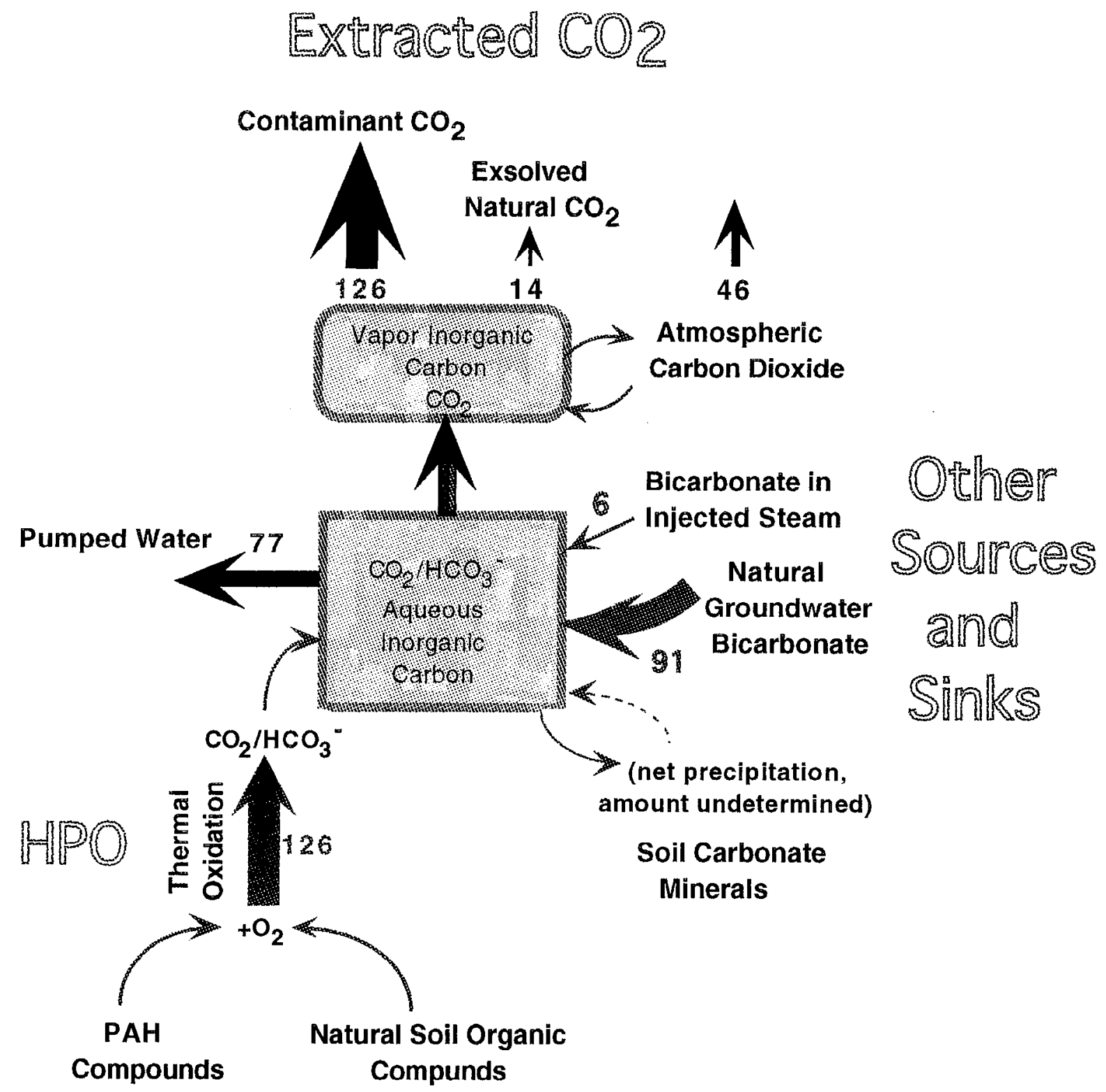

Figure 24. Flow chart showing the carbon sources and sinks in the Visalia field (after Aines et al., 1998). 
Geochemical Balance (Solubility Constrained)
Isotopic Balance (14-0)

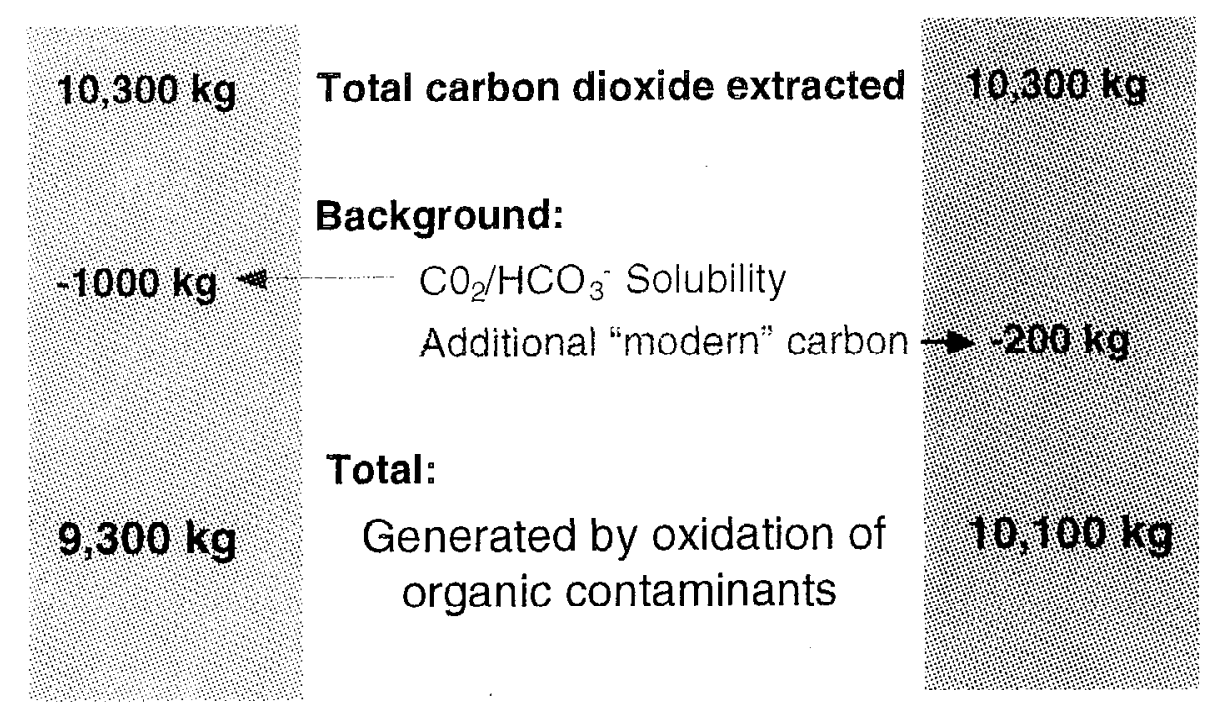

August 1 through October 14, 1997

Figure 25. Geochemical and Isotopic balances for Visalia extraction, August - October, 1997. 
Visalia Removal/Destruction

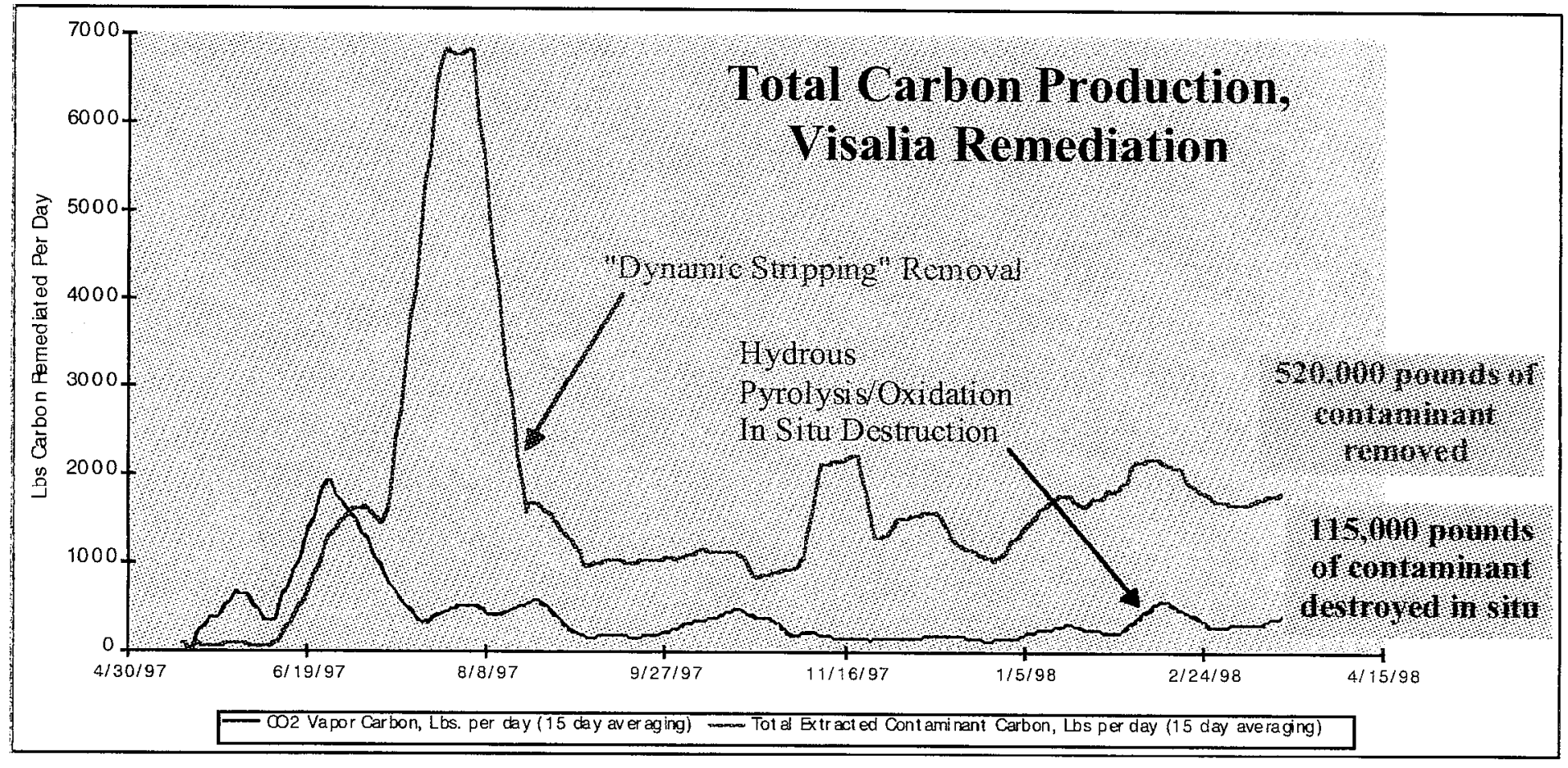

Figure 26. Visalia recovery from May, 1997-May, 1998. Contaminant removed obtained from total free product recovery, vapor and groundwater concentration(s) and flow rates. HPU d estruction estimated from extracted carbon dioxide in excess of geochem ical ba lance (in fl ow-ou tflow). 